\title{
Foreign Ownership of U.S. Safe Assets: Good or Bad?*
}

\author{
Jack Favilukis Sydney C. Ludvigson Stijn Van Nieuwerburgh \\ LSE NYU and NBER NYU NBER CEPR
}

Comments Welcome

First draft: February 10, 2011

This draft: July 27, 2011

*Favilukis: Department of Finance, London School of Economics, Houghton Street, London WC2A 2AE; Email: j.favilukis@lse.ac.uk, http://pages.stern.nyu.edu/ jfaviluk. Ludvigson: Department of Economics, New York University, 19 W. 4th Street, 6th Floor, New York, NY 10012; Email: sydney.ludvigson@nyu.edu; Tel: (212) 998-8927; http://www.econ.nyu.edu/user/ludvigsons/. Van Nieuwerburgh : Department of Finance, Stern School of Business, New York University, 44 W. 4th Street, 6th Floor, New York, NY 10012; Email: svnieuwe@stern.nyu.edu; Tel: (212) 998-0673; http://pages.stern.nyu.edu/ svnieuwe/. We are grateful to Gita Gopinath, and to seminar participants at USC and UC Davis for helpful comments. This material is based upon work supported by the National Science Foundation under Grant No. 1022915 to Ludvigson and Van Nieuwerburgh. Any errors or omissions are the responsibility of the authors. 


\title{
Foreign Ownership of U.S. Safe Assets: Good or Bad?
}

\begin{abstract}
The last 20 years have been marked by a sharp rise in international demand for U.S. reserve assets, or safe stores-of-value. This paper analyzes the welfare consequences of these fluctuations in international capital flows in a two-sector general equilibrium model with uninsurable idiosyncratic and aggregate risks. The model implies that the young benefit from a capital inflow due to lower interest rates, which reduce the costs of home ownership and of borrowing against higher expected future income. Middle-aged savers are hurt because they are crowded out of the safe bond market and exposed to greater systematic risk in equity and housing markets. Although they are partially compensated for this in equilibrium by higher risk premia, they still suffer from lower expected rates of return on their savings. By contrast, retired individuals, who are drawing down assets and who receive social security income that is least sensitive to the current aggregate state, benefit handsomely from the rise in asset values that accompanies a capital inflow. Under the "veil of ignorance," newborns gain from foreign purchases of the safe asset and would be willing to forgo up to $1 \%$ of lifetime consumption in order to avoid a large capital outflow. JEL: G11, G12, E44, E21
\end{abstract}




\section{Introduction}

The last 20 years have been marked by a sharp rise in international demand for U.S. reserve assets, or safe stores-of-value. This has led to an unprecedented degree of foreign ownership of U.S. government and government-backed debt, most of it held by Foreign Official Institutions such as central banks. In 1995, foreign holdings of U.S. Treasuries amounted to $17 \%$ of marketable Treasuries outstanding. By June 2008, foreigners owned $61 \%$ of all U.S. federal government debt. These trends have raised questions about the sustainability of large "global imbalances" between the demand for and supply of U.S. reserve assets, and they have invited speculation over the possible economic consequences of a sell-off of U.S. debt by foreign governments. ${ }^{1}$

Despite a vigorous academic debate on the question of whether global imbalances are a fundamentally benign or detrimental phenomenon, ${ }^{2}$ little is known about the potential welfare consequences of these changes in international capital flows, or of foreign ownership of U.S. safe assets in particular. We argue here that a complete understanding of the welfare implications requires a model with realistic heterogeneity, life-cycle dynamics, and plausible financial markets. For example, foreign purchases of domestic bonds reduce interest rates, which could benefit the young who are in a borrowing stage of the life-cycle. On the other hand, demand for U.S. bonds by foreign governmental holders crowds domestic savers out of the safe bond market, exposing them to greater systematic risk in equity and housing markets. Thus, middle-aged savers are potentially hurt both by lower interest rates and rates of return, and by greater exposure to systematic risk. In the limit, as rising governmental ownership drives domestic interest rates to zero, non-governmental investors are forced to take on ever greater risk with their savings in order to earn a non-negligible return.

This paper analyzes the welfare consequences of foreign ownership of U.S. safe assets. We study a two-sector general equilibrium model of housing and non-housing production where heterogeneous agents face limited opportunities to insure against idiosyncratic and aggregate risks. The model is sufficiently general so as to account for the endogenous interactions among financial and housing wealth, output and investment, interest rates, consumption and wealth inequality and risk premia in both housing and equity assets. The model economy is populated by a large number of overlapping generations of households who receive utility from both housing and nonhousing consumption and who face a stochastic life-cycle earnings

\footnotetext{
${ }^{1}$ See for example, Obstfeld and Rogoff (2009), Bernanke (2011) and Fahri, Gourinchas, and Rey (2011).

${ }^{2}$ See Mendoza, Quadrini, and Rios-Rull (2007), Caballero, Fahri, and Gourinchas (2008a), Caballero, Fahri, and Gourinchas (2008b), Obstfeld and Rogoff (2009), and Caballero (2009).
} 
profile. We introduce market incompleteness by modeling heterogeneous agents who face idiosyncratic and aggregate risks against which they cannot perfectly insure, and by imposing collateralized borrowing constraints on households. A crucial source of aggregate risk in the model is a shock to foreign ownership of the domestic riskless bond, calibrated to match U.S. data. This shock affects asset values and welfare because it alters the effective supply of safe assets available to domestic households.

An important aspect of recent patterns in international capital flows is that foreign demand for U.S. Treasury securities is dominated by Foreign Official Institutions who take extremely inelastic positions, implying that when these holders receive funds to invest they buy U.S. Treasuries regardless of price (Krishnamurthy and Vissing-Jorgensen (2010)). Moreover, the persistent and growing U.S. trade deficits since 1994 have been financed almost exclusively by an upward trend in net foreign holdings of U.S. assets considered to be safe stores-of-value (i.e., Treasury and Agency debt). By contrast, net foreign holdings of risky securities have fluctuated near zero. In this paper, we study the welfare implications of precisely this kind of international capital flow, namely fluctuations in net foreign inflows by governmental holders who inelastically place all of their funds in the domestic riskless bond.

The model economy implies that foreign purchases (or sales) of the safe asset have quantitatively important distributional consequences, reflecting tradeoffs between generations, and between economic groups distinguished by wealth and income. Welfare outcomes are influenced by the endogenous response of asset markets to fluctuations in foreign holdings of the safe asset. A capital inflow has an economically important downward impact on the risk-free interest rate, consistent with empirical evidence. ${ }^{3}$ Although lower interest rates boost equity and home prices relative to measures of fundamental value, foreign purchases of the domestic riskless bond also reduce the effective supply of the safe asset, thereby exposing domestic savers to greater systematic risk in equity and housing markets. In response, risk premia on housing and equity assets rise, substantially (but not fully) offsetting the stimulatory impact of lower interest rates on home and equity prices.

These factors imply that the young and the old experience welfare gains from a capital inflow, while middle-aged savers suffer. The young benefit from lower interest rates, which reduce the costs of home ownership and of borrowing in anticipation of higher expected future income. Middle-aged savers are hurt because they are crowded out of the safe bond market and exposed to greater systematic risk in equity and housing markets. Although they are partially compensated for this in equilibrium by higher risk-premia, they still suffer

\footnotetext{
${ }^{3}$ See Krishnamurthy and Vissing-Jorgensen (2010), Warnock and Warnock (2009), and Bernanke (2011).
} 
from lower expected rates of return on their savings. By contrast, retired individuals suffer less from lower expected rates of return, since they are drawing down assets at the end of life. They also receive social security income that is less sensitive to the current aggregate state than is labor income, making them more insulated from systematic risk. Taken together, these factors imply that the oldest retirees experience a significant net gain from even modest increases in asset values that may accompany a capital inflow. We also compute welfare consequences for groups that vary according to wealth and income, as well as an ex-ante measure for agents just being born. Under the "veil of ignorance," newborns benefit from foreign purchases of the safe asset and would be willing to forgo up to $1 \%$ of lifetime consumption in order to avoid a large capital outflow.

This paper is related to a literature on incomplete markets and equity pricing, ${ }^{4}$ as well as a literature on incomplete markets and housing, or durables more generally. ${ }^{5}$ The model in this paper has many of the same features as the incomplete markets model studied in Favilukis, Ludvigson, and Van Nieuwerburgh (2009) (FLVN). Unlike the related incomplete markets literature, FLVN study the economic impact of foreign purchases of U.S. assets through a comparison of stochastic steady states. But that paper differs from the present one in two important ways. First, FLVN focused on the valuation effects of changes in housing finance and did not study the welfare consequences of international capital flows, as here. Second, the model studied in FLVN specified capital flows as a fixed fraction of output, whereas the present paper introduces an additional source of aggregate uncertainty (a shock to foreign holdings relative to output) that cannot be insured away. This additional source of aggregate risk is a significant extension of the model, since it introduces two new state variables over which agents must form expectations; nevertheless it has important implications both for asset markets and welfare.

This paper is also related to the literature on global imbalances in international capital markets and, less directly, to the literature on Sudden Stops, which studies reversals of international capital flows in emerging economies. ${ }^{6}$ Caballero, Fahri, and Gourinchas (2008a)

\footnotetext{
${ }^{4}$ See Aiyagari and Gertler (1991), Telmer (1993), Lucas (1994), Heaton and Lucas (1996), Basak and Cuoco (1998), Luttmer (1999), Lustig and Van Nieuwerburgh (2005), Gomes and Michaelides (2008), Storesletten, Telmer, and Yaron (2007), and Favilukis (2008).

${ }^{5}$ See Fernández-Villaverde and Krueger (2005), Campbell and Hercowitz (2006), Ortalo-Magné and Rady (2006), Peterson (2006), Ríos-Rull and Sánchez-Marcos (2006), Lustig and Van Nieuwerburgh (2007, 2008), Piazzesi and Schneider (2008), Corbae and Quintin (2009), Kiyotaki, Michaelides, and Nikolov (2008), Favilukis, Ludvigson, and Van Nieuwerburgh (2009), and Iacoviello and Pavan (2009).

${ }^{6}$ The application of this paper is to the developed economy of the United States. For a classification of
} 
and Caballero and Krishnamurthy (2009) (discussed further below) study the economic consequences of capital inflows in representative agent economies, but do not study the welfare outcomes of these flows. A premise of this paper is that a complete understanding of the welfare implications requires a model with reasonable heterogeneity, life-cycle dynamics, and plausible financial markets. Although the model we study does not match every aspect of the data perfectly, it produces reasonable implications for financial markets on key dimensions that are likely to be important for welfare, such as equity and housing risk premia and Sharpe ratios.

The rest of this paper is organized as follows. The next section discusses the recent history of foreign purchases of U.S. government securities, and how we model them. Section 3 describes the model, including the dynamics of foreign holdings of domestic bonds, the equilibrium, the welfare measures, and the calibration. Section 4 presents the results, focusing on the macroeconomic, asset market, and welfare consequences of fluctuations in foreign ownership of the domestic safe asset. Section 5 summarizes and concludes.

\section{Modeling Recent Trends in International Capital Flows}

A key development in the international capital markets of recent years is the surge in foreign ownership of U.S. Government debt and Government-backed debt. Foreign ownership of U.S. Treasuries (T-bonds and T-notes) increased from $\$ 118$ billion in 1984, or $13.5 \%$ of marketable Treasuries outstanding, to $\$ 3.6$ trillion in 2008 , or $61 \%$ of marketable Treasuries (Figure 1). Foreign holdings of U.S. agency and Government Sponsored Enterprise-backed agency securities quintupled between 2000 and 2007, rising from $\$ 261$ billion to $\$ 1.3$ trillion, or from $7 \%$ to $21 \%$ of total agency debt. Foreign holdings of U.S. Treasury (short- and long-term) and long-term Agency debt (we have no data on short-term Agency debt) as a fraction of GDP more than doubled from $14 \%$ to $35 \%$ over the period 2000-2008 and stands at $34 \%$ at the end of our sample in June 2010.

Figure 2 shows the fraction of foreign holdings relative to trend U.S. gross domestic product (GDP). The figure reports both the raw series, as well as a series adjusted in 2009 and 2010 for the large increase in the quantity of Treasury debt outstanding that occurred in 2009. The adjusted series equals the level of foreign holdings as a fraction of trend GDP that would have occurred in 2009 and 2010 had Treasury debt outstanding as a fraction of trend GDP been fixed at its 2008 level. For the unadjusted series, foreign holdings more than

Sudden Stops in emerging economies, see Calvo, Izquierdo, and Talvi (2006). 
doubled from 2001 to 2010, increasing from $15 \%$ of trend GDP in 2001 to $35.5 \%$ by June 2010. But the adjusted series implies that foreign holdings were just $24.6 \%$ of trend GDP in June 2010, 10.6\% lower than the unadjusted figure. This suggests that an unwinding of global imbalances, at least relative to trend GDP, may have been underway by the end of our sample.

The rise in net holdings by foreigners over time has coincided with downward trend in interest rates. Both 30-year fixed rate mortgages and the 10-year Treasury bond yield trended downward, with mortgage rates declining from around 18 percent in the early 1980s to near 6 percent by the end of 2007, to an all-time low of $4.2 \%$ in October 2010. The decline in nominal rates was not merely attributable to a decline in inflation: the real annual interest rate on the ten-year Treasury bond fell from $3.5 \%$ at the start of 2000 to $-0.2 \%$ at the end of 2008 using the consumer price index as a measure of inflation. It subsequently increased to $1.6 \%$ by the end of 2010 . A similar percentage decline in the real rate is indicated from data on Treasury Inflation Protected bonds. ${ }^{7}$

We model changes in net capital flows directly and calibrate them to match U.S. data, following a stochastic process specified below. We do not specify the sources of these changes or take a stand on the model of international trade that gives rise to them in equilibrium. Note that it is unnecessary to do so to close the model: in the resource constraint of the economy, the trade balance is simply the negative of the net change in the value of foreign holdings of domestic assets, a variable that endogenously influences the quantity of domestic consumption and investment relative to domestic output.

By not modeling the mechanics of trade adjustment, it is possible that we could miss one channel (often emphasized for small open economies or for developing economies) through which changes in the terms of trade influence measured total factor productivity (TFP) of the manufacturing sector. Specifically, if imported and domestic inputs are imperfect substitutes, then movements in the relative prices of these goods can impact firm productivity, either by altering the number of varieties used or by altering the quality mix of domestic and foreign inputs. Gopinath and Neiman (2011) study the Argentinean economy and find that such trade adjustments deliver quantitatively important declines in manufacturing TFP.

\footnotetext{
${ }^{7}$ To compute the real interest rate, we use the 10-year constant maturity Treasury rate and subtract realized inflation over the preceding 12 months. We then take a 12-month moving average of this series to smooth it out. We also investigate 10-year Treasury Inflation Protected (TIPS) rates, which are available from 2003 onward from FRED II and from McCulloch from 1997 to 2003. Using the same 12 month moving average, we find that real 10-year TIPS yields were $4.0 \%$ at the start of 2000 and fall to $1.8 \%$ by the end of 2008. They fall further to $1.15 \%$ by the end of 2010 .
} 
While such a terms-of-trade channel might be important for the U.S. economy, we do not pursue modeling it here, for two reasons. First, the added complexity would greatly complicate the numerical solution procedure, requiring us to compromise other aspects of the framework. Second and more significantly, there appears to be little if any direct evidence on how important such a channel might be for the U.S. manufacturing sector, let alone for the U.S. economy as a whole. For example, if a trade balance movement coincides with changes in the usage of all inputs (domestic and foreign), with no movements in relative shares, this channel is less important. Also, if U.S. domestic inputs can be substituted for foreign inputs, then this channel is again weakened. More research is needed to determine how significant such channels are for the U.S. economy.

Interest rates in the model are determined in equilibrium by a market clearing condition for bondholders. We introduce foreign demand for domestic bonds into the market clearing condition. Hereafter we refer to foreign ownership of domestic riskless asset interchangeably as foreign capital or external leverage. This foreign capital is modeled as owned by governmental holders who inelastically place all of their funds in domestic riskless bonds. We do this for two reasons. First, as recent data shows, Foreign Official Institutions own the vast majority of U.S. Treasuries: in June 2010 Foreign Official Institutions held $75 \%$ of all foreign holdings of U.S. Treasuries. As explained in Kohn (2002), government entities have specific regulatory and reserve currency motives for holding U.S. Treasuries and face both legal and political restrictions on the type of assets that can be held, forcing them into safe securities. Second, Krishnamurthy and Vissing-Jorgensen (2010) find that demand for U.S. Treasury securities by governmental holders is extremely inelastic, implying that when these holders receive funds to invest they buy U.S. Treasuries, regardless of their price. In the model, we assume domestic borrowers may obtain credit collateralized by home equity at a fixed interest rate spread with the governmental rate. ${ }^{8}$ Because our model abstracts from default, we set this spread to zero in our calibration.

The model here is intended to study changes in capital flows that result from changes in the net foreign holdings of the domestic safe asset. We do not model trends in net foreign holdings of risky securities. Figure 3 shows why: net foreign holdings of risky securities as a fraction of U.S. Trend GDP have hovered close to zero since 1994, even as net foreign holdings of safe assets (defined as U.S. Treasury and Agency securities) have soared. Thus

\footnotetext{
${ }^{8}$ In practice, government debt and mortgage debt are not dissimilar. After the start of the conservatorship of Freddie Mac and Fannie Mae in September 2008, half of government debt was Government-sponsored Agency debt that backed mortgages.
} 
Figure 3 shows that all of the upward trend in net foreign holdings of U.S. securities since 1994 has been the result of an upward trend in net foreign holdings of safe assets; net foreign holdings of risky assets are almost exactly zero in June of 2010.

\section{The Model}

This section describes the model economy with two productive sectors. Time is discrete and each period $t$ corresponds to a year. The economy grows deterministically at rate $g$. The exogenous aggregate shocks of the model include a stationary shock to foreign capital relative to trend GDP, and stationary technology shocks $Z_{k, t}$, one to each of the two sectors indexed by $k$, that have both a deterministic component and stochastic component, i.e., $Z_{k, t}=\exp (g t) z_{k, t}$, where $z_{k, t}$ is a stationary technology shock. The variable exp $(g t)$ is trend output, interchangeably denoted $\bar{Y}_{t} \equiv \exp (g t)$.

\subsection{Firms}

The production side of the economy consists of two sectors. One sector produces the nonhousing consumption good, and the other sector produces the housing good. We refer to the first as the "consumption sector" and the second as the "housing sector." A house in our model is a residential durable asset that provides utility to the household, is illiquid (expensive to trade), and can be used as collateral in debt obligations. In each period, a representative firm in each sector chooses labor (which it rents) and investment in capital (which it owns) to maximize the value of the firm to its owners.

\subsubsection{Consumption Sector}

Denote output in the consumption sector as

$$
Y_{C, t} \equiv Z_{C, t}^{1-\alpha} K_{C, t}^{\alpha} N_{C, t}^{1-\alpha}
$$

where $Z_{C, t}$ is the stochastic productivity level at time $t, K_{C}$ is the capital stock in the consumption sector, $\alpha$ is the share of capital, and $N_{C}$ is the quantity of labor input in the consumption sector. Let $I_{C}$ denote investment in the consumption sector. The firm's capital

stock $K_{C, t}$ accumulates over time subject to proportional adjustment costs, $\phi_{C}\left(\frac{I_{C, t}}{K_{C, t}}\right) K_{C, t}$, modeled as a deduction from the earnings of the firm. The firm does not issue new shares and 
finances its capital stock entirely through retained earnings. The dividends to shareholders are equal to

$$
D_{C, t}=Y_{C, t}-\mathcal{W}_{t} N_{C, t}-I_{C, t}-\phi_{C}\left(\frac{I_{C, t}}{K_{C, t}}\right) K_{C, t} .
$$

The firm maximizes the present discounted value $V_{C, t}$ of a stream of dividends:

$$
V_{C, t}=\max _{N_{C, t}, I_{C, t}} E_{t} \sum_{k=0}^{\infty} \frac{\beta^{k} \Lambda_{t+k}}{\Lambda_{t}} D_{C, t}
$$

where $\frac{\beta^{k} \Lambda_{t+k}}{\Lambda_{t}}$ is a stochastic discount factor discussed below, and $\mathcal{W}_{t}$ is the wage rate (equal across sectors in equilibrium). The evolution equation for the firm's capital stock is

$$
K_{C, t+1}=(1-\delta) K_{C, t}+I_{C, t}
$$

where $\delta$ is the depreciation rate of the capital stock.

\subsubsection{Housing Sector}

The housing firm's problem is analogous to the problem solved by the representative firm in the consumption sector, except that housing production utilizes an additional fixed factor of production, $\mathcal{L}_{t}$, representing a combination of land and government permits for residential construction. ${ }^{9}$ Denote output in the residential housing sector as

$$
Y_{H, t}=Z_{H, t}\left(\mathcal{L}_{t}\right)^{1-\phi}\left(K_{H, t}^{\nu} N_{H, t}^{1-\nu}\right)^{\phi}
$$

$Y_{H, t}$ represents construction of new housing (residential investment), $1-\phi$ is the share of land/permits in housing production, and $\nu$ is the share of capital in the construction component $\left(K_{H, t}^{\nu} N_{H, t}^{1-\nu}\right)$ of housing production. Variables denoted with an " $H$ " subscript are defined exactly as above for the consumption sector but now pertain to the housing sector, e.g., $Z_{H, t}$ denotes the stochastic productivity level in the housing sector.

We assume that, each period, the government makes available a fixed supply $\overline{\mathcal{L}}$ of land/permits for residential construction by renting them at the competitive rental rate equal to the marginal product of $\mathcal{L}_{t}$. The proceeds from land rentals are used by the government to finance (wasteful) government spending $G_{t}$. When a house is sold, the government

\footnotetext{
${ }^{9}$ Glaeser, Gyourko, and Saks (2005) argue that the increasing value of land for residential development is tied to government-issued construction permits, rather than to the acreage itself. We do not distinguish between these two forms of productive input and instead aggregate both forms into a single factor $\mathcal{L}_{t}$.
} 
issues a transferable lease for the land/permits in perpetuity at no charge to the homeowner. Thus, the buyer of the home operates as owner even though, by eminent domain, the government retains the legal right to the land/permits.

Let $p_{t}^{H}$ denote the relative price of housing in units of the non-housing consumption good and let $p_{t+k}^{L}$ denote the price of land/permits. Notice that $p_{t}^{H}$ is the time $t$ price of a unit of housing of fixed quality and quantity; it corresponds to the value of a national house-price index. The dividends to shareholders in the housing sector are given by

$$
D_{H, t}=p_{t}^{H} Y_{H, t}-p_{t}^{L} \mathcal{L}_{t}-\mathcal{W}_{t} N_{H, t}-I_{H, t}-\phi_{H}\left(\frac{I_{H, t}}{K_{H, t}}\right) K_{H, t} .
$$

The housing firm maximizes

$$
V_{H, t}=\max _{N_{H, t}, I_{H, t}} E_{t} \sum_{k=0}^{\infty} \frac{\beta^{k} \Lambda_{t+k}}{\Lambda_{t}} D_{H, t} .
$$

Capital in the housing sector evolves:

$$
K_{H, t+1}=(1-\delta) K_{H, t}+I_{H, t} .
$$

Note that $Y_{H, t}$ represents residential construction; thus the law of motion for the aggregate residential housing stock $H_{t}$ is

$$
H_{t+1}=\left(1-\delta_{H}\right) H_{t}+Y_{H, t},
$$

where $\delta_{H}$ denotes the depreciation rate of the housing stock.

\subsection{Risky Asset Returns}

The firms' values $V_{H, t}$ and $V_{C, t}$ are the cum dividend values, measured before the dividend is paid out. Thus the cum dividend returns to shareholders in the housing sector and the consumption sector are defined, respectively, as

$$
R_{Y_{H}, t+1}=\frac{V_{H, t+1}}{\left(V_{H, t}-D_{H, t}\right)} \quad R_{Y_{C}, t+1}=\frac{V_{C, t+1}}{\left(V_{C, t}-D_{C, t}\right)} .
$$

We define $V_{j, t}^{e}=V_{j, t}-D_{j, t}$ for $j=H, C$ to be the $e x$ dividend value of the firm. ${ }^{10}$

\footnotetext{
${ }^{10}$ Using the $e x$ dividend value of the firm the return reduces to the more familiar $e x$ dividend definition: $R_{j, t+1}^{e}=\frac{V_{j, t+1}^{e}+D_{j, t+1}}{V_{j, t}^{e}}$.
} 


\subsection{Individuals}

The economy is populated by $A$ overlapping generations of individuals, indexed by $a=$ $1, \ldots, A$, with a continuum of individuals born each period. Individuals live through two stages of life, a working stage and a retirement stage. Adult age begins at age 21, so a equals this effective age minus 20. Agents live for a maximum of $A=80$ (100 years). Workers live from age $21(a=1)$ to $65(a=45)$ and then retire. Retired workers die with an agedependent probability calibrated from life expectancy data. The probability that an agent is alive at age $a+1$ conditional on being alive at age $a$ is denoted $\pi_{a+1 \mid a}$. Upon death, any remaining net worth of the individual in that period is counted as terminal "consumption," e.g., funeral and medical expenses.

Individuals have an intraperiod utility function given by

$$
U\left(C_{a, t}, H_{a, t}\right)=\frac{\widetilde{C}_{a, t}^{1-\frac{1}{\sigma}}}{1-\frac{1}{\sigma}} \quad \widetilde{C}_{a, t}=\left[\chi C_{a, t}^{\frac{\varepsilon-1}{\varepsilon}}+(1-\chi) H_{a, t}^{\frac{\varepsilon-1}{\varepsilon}}\right]^{\frac{\varepsilon}{\varepsilon-1}}
$$

where $\widetilde{C}$ is referred to as composite consumption, $C_{a, t}$ is non-housing consumption of an individual of age $a$, and $H_{a, t}$ is the stock of housing, $1 / \sigma$ is the coefficient of relative risk aversion, $\chi$ is the relative weight on non-housing consumption in utility, and $\varepsilon$ is the constant elasticity of substitution between $C$ and $H$. Implicit in this specification is the assumption that the service flow from houses is proportional to the stock $H_{a, t}$.

Financial market trade is limited to a one-period riskless bond and to risky capital, where the latter is restricted to be a mutual fund of equity in the housing and consumption sectors. The mutual fund is a value-weighted portfolio with return

$$
R_{K, t+1}=\frac{V_{H, t}^{e}}{V_{H, t}^{e}+V_{C, t}^{e}} R_{Y_{H}, t+1}+\frac{V_{C, t}^{e}}{V_{H, t}^{e}+V_{C, t}^{e}} R_{Y_{C}, t+1} .
$$

The gross bond return is denoted $R_{f, t}=\frac{1}{q_{t-1}}$, where $q_{t-1}$ is the bond price known at time $t-1$. Individuals are born with no initial endowment of risky capital or bonds.

Individuals are heterogeneous in their labor productivity. To denote this heterogeneity, we index individuals $i$. Before retirement households supply labor inelastically. The stochastic process for individual income for workers is the product of $\mathcal{W}_{t}$, the aggregate wage per unit of productivity, and $L_{a, t}^{i}$, the individual's labor endowment (hours times an individual-specific productivity factor). Labor productivity is specified by a deterministic age-specific profile, $G_{a}$, and an individual shock $Z_{t}^{i}$ :

$$
\begin{aligned}
L_{a, t}^{i} & =G_{a} Z_{t}^{i} \\
\ln \left(Z_{t}^{i}\right) & =\ln \left(Z_{t-1}^{i}\right)+\epsilon_{t}^{i}, \quad \epsilon_{t}^{i} \sim \text { i.i.d. }\left(0, \sigma_{t}^{2}\right),
\end{aligned}
$$


where $G_{a}$ is a deterministic function of age capturing a hump-shaped profile in life-cycle earnings and $\epsilon_{a, t}^{i}$ is a stochastic i.i.d. shock to individual earnings. To capture countercyclical variation in idiosyncratic risk of the type documented by Storesletten, Telmer, and Yaron (2004), we use a two-state specification for the variance of idiosyncratic earnings shocks:

$$
\sigma_{t}^{2}=\left\{\begin{array}{ll}
\sigma_{E}^{2} & \text { if } Z_{C, t} \geq E\left(Z_{C, t}\right) \\
\sigma_{R}^{2} & \text { if } Z_{C, t}<E\left(Z_{C, t}\right)
\end{array} \quad, \quad \sigma_{R}^{2}>\sigma_{E}^{2}\right.
$$

This specification implies that the variance of idiosyncratic labor earnings is higher in "recessions" $\left(Z_{C, t} \leq E\left(Z_{C, t}\right)\right)$ than in "expansions" $\left(Z_{C, t} \geq E\left(Z_{C, t}\right)\right)$. The former is denoted with an " $R$ " subscript, the latter with an " $E$ " subscript. The counter-cyclical increase in income dispersion is an important contributor to the equity risk premium in our model (see Krueger and Lustig (2010)). Finally, labor earnings are taxed at rate $\tau$ in order to finance social security retirement income.

At age $a$, agents enter the period with wealth invested in bonds, $B_{a}^{i}$, and shares $\theta_{a}^{i}$ of risky capital. The total number of shares outstanding of the risky asset is normalized to unity. We rule out short-sales in the risky asset,

$$
\theta_{a, t}^{i} \geq 0
$$

An individual who chooses to invest in the mutual fund pays a fixed, per-period participation cost, $F_{K, t}$.

We assume that the housing owned by each individual depreciates at rate $\delta_{H}$, the rate of depreciation of the aggregate housing stock. Households may choose to increase the quantity of housing consumed at time $t+1$ by making a net investment $H_{a, t+1}^{i}-\left(1-\delta_{H}\right) H_{a, t}^{i}>0$. Because houses are illiquid, it is expensive to change housing consumption. An individual who chooses to change housing consumption pays a transaction cost $F_{H, t}^{i}$. Denote the sum of the per period equity participation cost and housing transaction cost for individual $i$ as

$$
F_{t}^{i} \equiv F_{H, t}^{i}+F_{K, t}
$$

Define the individual's gross financial wealth at time $t$ as

$$
W_{a, t}^{i} \equiv \theta_{a, t}^{i}\left(V_{C, t}^{e}+V_{H, t}^{e}+D_{C, t}+D_{H, t}\right)+B_{a, t}^{i} .
$$

The budget constraint for an agent of age $a$ who is not retired is

$$
\begin{aligned}
C_{a, t}^{i}+B_{a+1, t+1}^{i} q_{t}+\theta_{a+1, t+1}^{i}\left(V_{C, t}^{e}+V_{H, t}^{e}\right) \leq & W_{a, t}^{i}+(1-\tau) \mathcal{W}_{t} L_{a, t}^{i} \\
& +p_{t}^{H}\left(\left(1-\delta_{H}\right) H_{a, t}^{i}-H_{a+1, t+1}^{i}\right)-F_{t}^{i}
\end{aligned}
$$




$$
W_{a+1, t+1}^{i} \geq-(1-\varpi) p_{t}^{H} H_{a, t+1}^{i}, \quad \forall a, t
$$

where $\tau$ is a social security tax rate and where

$$
\begin{aligned}
& F_{H, t}^{i}= \begin{cases}0, & H_{a+1, t+1}^{i}=\left(1-\delta_{H}\right) H_{a, t}^{i} \\
\psi_{0}+\psi_{1} p_{t}^{H} H_{a, t}^{i}, & H_{a+1, t+1}^{i} \neq\left(1-\delta_{H}\right) H_{a, t}^{i}\end{cases} \\
& F_{K, t}= \begin{cases}0 & \text { if } \theta_{a+1, t+1}^{i}=0 \\
\bar{F} & \text { if } \theta_{a+1, t+1}^{i}>0\end{cases}
\end{aligned}
$$

$F_{H, t}^{i}$ is the housing transactions cost which contains both a fixed and variable component and depends on age only through $H_{a, t}^{i}$. Equation (7) is the collateral constraint, where $0 \leq \varpi \leq 1$. It says that households may borrow no more than a fraction $(1-\varpi)$ of the value of housing, implying that they must post collateral equal to a fraction $\varpi$ of the value of the house. This constraint can be thought of as a down-payment constraint for new home purchases, but it also encompasses collateral requirements for home equity borrowing against existing homes. The constraint gives the maximum combined loan-to-value (LTV) ratio for first and second mortgages and home equity withdrawal. Notice that if the price $p_{t}^{H}$ of the house rises and nothing else changes, the individual can finance a greater level of consumption of both housing and nonhousing goods and services.

Two points about the collateral constraint above are worth noting. First, it applies to any borrowing against home equity, not just to mortgages. Second, borrowing takes place using one-period debt. Thus, an individual's borrowing capacity fluctuates period-by-period with the value of the house.

We also prevent individuals from buying stock on margin. If the individual is a net borrower, this means we restrict holdings of the risky asset to be zero, $\theta_{a+1, t+1}^{i}=0$. This restriction is stated mathematically as follows:

$$
\begin{gathered}
\text { if } W_{a, t}^{i}+(1-\tau) \mathcal{W}_{t} L_{a, t}^{i}-\left(C_{a, t}^{i}+p_{t}^{H}\left(H_{a+1, t+1}^{i}-\left(1-\delta_{H}\right) H_{a, t}^{i}\right)-F_{t}^{i}\right)<0 \\
\text { then } \quad B_{a+1, t+1}^{i}<0, \quad \theta_{a+1, t+1}^{i}=0 .
\end{gathered}
$$

Net lenders may take a positive position in the risky asset but may not short the bond to do so:

$$
\begin{gathered}
\text { if } W_{a, t}^{i}+(1-\tau) \mathcal{W}_{t} L_{a, t}^{i}-\left(C_{a, t}^{i}+p_{t}^{H}\left(H_{a+1, t+1}^{i}-\left(1-\delta_{H}\right) H_{a, t}^{i}\right)-F_{t}^{i}\right) \geq 0 \\
\text { then } \quad B_{a+1, t+1}^{i} \geq 0, \quad \theta_{a+1, t+1}^{i} \geq 0 .
\end{gathered}
$$

Let $Z_{a r}^{i}$ denote the value of the stochastic component of individual labor productivity, $Z_{a, t}^{i}$, during the last year of working life. Each period, retired workers receive a government 
pension $P E_{a, t}^{i}=Z_{a r}^{i} X_{t}$, where $X_{t}=\mathcal{W}_{t} \tau\left(\frac{N^{W}}{N^{R}}\right)$ is the pension determined by a pay as you go system, and $N^{W}$ and $N^{R}$ are the numbers of working age and retired households. ${ }^{11}$ For agents who have reached retirement age, the budget constraint is identical to that for workers (6) except that wage income $(1-\tau) \mathcal{W}_{t} L_{a, t}^{i}$ is replaced by pension income $P E_{a, t}^{i}$.

\subsection{Stochastic Process for Capital Flows}

Let $B_{F, t}$ denote the stochastic supply of foreign capital to the domestic bond market, i.e., $B_{F, t}>0$ represents a net positive bond position by foreign holders. Foreign purchases of the riskless asset affect an individual's optimization problem by influencing the price of bonds and appear directly in the market clearing condition for the bond market (given below). In addition, the aggregate resource constraint for this economy (also given below) implies that the net change in the value of foreign capital, or the trade balance, influences current spending relative to current resources. For this reason, both $B_{F, t+1}$ and $B_{F, t}$ are aggregate state variables as of time $t$. (Note that, given the timing convention of the budget constraint (6), $B_{F, t+1}$ is beginning of period debt and therefore is known at time $t$.) A positive net foreign asset inflow is identically equivalent to a trade deficit (negative trade balance), which is reflected in the aggregate resource constraint of the economy.

Let GDP be defined as $Y_{t} \equiv Y_{C, t}+p^{H} Y_{H, t}+C_{H, t}$, where $C_{H, t}$ is the aggregate value of housing consumption across all households in the economy. Given a probability law for stochastic foreign holdings, households form beliefs about their evolution. Let $\bar{Y}_{t}$ denote trend GDP, $\exp (g t)$, as explained above. We assume that households form beliefs according to a stochastic process for foreign holdings relative to trend GDP, $b_{F, t} \equiv B_{F, t} / \bar{Y}_{t}$, assumed to evolve according to a first-order autoregressive process:

$$
b_{F, t+1}=\left(1-\rho_{F}\right) \bar{b}+\rho_{F} b_{F, t}+\sigma_{F} \eta_{t+1} .
$$

Below we explain how this process is calibrated to historical data on foreign holdings of U.S. Treasury debt (available from the Department of Treasury, U.S. Government).

\footnotetext{
${ }^{11}$ The decomposition of the population into workers and retirees is determined from life-expectancy tables as follows. Let $X$ denote the total number of people born each period. (In practice this is calibrated to be a large number in order to approximate a continuum.) Then $N^{W}=45 \cdot X$ is the total number of workers. Next, from life expectancy tables, if the probability of dying at age $a>45$ is denoted $p_{a}$ then $N^{R}=\sum_{a=46}^{80}\left(1-p_{a}\right) X$ is the total number of retired persons.
} 


\subsection{Law of Motion for State Variables}

Let $Z_{t} \equiv\left(Z_{C, t}, Z_{H, t}, B_{F, t}, B_{F, t+1}\right)^{\prime}$ denote the exogenous aggregate states. The total aggregate state of the economy is a pair, $(Z, \mu)$, where $\mu$ is a measure defined over $\mathcal{S}=(\mathcal{A} \times \mathcal{Z} \times \chi \times \mathcal{H})$, where $\mathcal{A}=\{1,2, \ldots A\}$ is the set of ages, where $\mathcal{Z}$ is the set of all possible idiosyncratic shocks, where $\chi$ is the set of all possible beginning-of-period financial wealth realizations, and where $\mathcal{H}$ is the set of all possible beginning-of-period housing wealth realizations. That is, $\mu$ is a distribution of agents across ages, idiosyncratic shocks, financial and housing wealth. The presence of aggregate shocks implies that $\mu$ evolves stochastically over time. We specify a law of motion, $\Gamma$, for $\mu$,

$$
\mu_{t+1}=\Gamma\left(\mu_{t}, Z_{t}, Z_{t+1}\right)
$$

\subsection{Stochastic Discount Factor}

The stochastic discount factor (SDF), $\frac{\beta \Lambda_{t+1}}{\Lambda_{t}}$, appears in the dynamic value maximization problem (1) and (2) undertaken by each representative firm. We assume that the representative firm discounts future profits using a weighted average of the individual shareholders' MRS in non-housing consumption, $\frac{\beta \partial U / \partial C_{a+1, t+1}^{i}}{\partial U / \partial C_{a, t}^{i}}$, where the weights, $\theta_{a, t}^{i}$, correspond to the shareholder's proportional ownership in the firm. (For a detailed discussion of this assumption, see FLVN). Let $\frac{\beta \Lambda_{t+1}}{\Lambda_{t}}$ denote this weighted average. Recalling that the total number of shares in the risky portfolio is normalized to unity, we have

$$
\begin{gathered}
\frac{\beta \Lambda_{t+1}}{\Lambda_{t}} \equiv \int_{\mathcal{S}} \theta_{a+1, t+1}^{i} \frac{\beta \partial U / \partial C_{a+1, t+1}^{i} d \mu}{\partial U / \partial C_{a, t}^{i}} d \mu\left[\left(\frac{C_{a+1, t+1}^{i}}{C_{a, t}^{i}}\right)^{-\frac{1}{\sigma}}\left[\frac{\chi+(1-\chi)\left(\frac{H_{a+1, t+1}^{i}}{C_{a+1, t+1}^{i}}\right)^{\frac{\varepsilon-1}{\varepsilon}}}{\chi+(1-\chi)\left(\frac{H_{a, t}^{i}}{C_{a, t}^{i}}\right)^{\frac{\varepsilon-1}{\varepsilon}}}\right] .\right. \\
\frac{\beta \partial U / \partial C_{a+1, t+1}^{i}}{\partial U / \partial C_{a, t}^{i}}=\beta
\end{gathered}
$$

Since we weight each individual's MRS by its proportional ownership (and since shortsales in the risky asset are prohibited), only those households who are long in the risky asset (shareholders) will receive non-zero weight in the SDF. We check that our equilibrium is not quantitatively sensitive to this assumption on ownership control. ${ }^{12}$

\footnotetext{
${ }^{12}$ This insensitivity is predicted in a wide class of incomplete markets models in which the firm's objective is value maximization. For example, Carceles Poveda and Coen-Pirani (2009) show that the equilibrium allocations in a many incomplete markets models is invariant to the choice of stochastic discount factor within the set that includes the MRS of any household (or any weighted average of these) for whom the
} 


\subsection{Housing and Equity Returns}

Abstracting from transactions costs and borrowing constraints, the first-order condition for optimal housing choice is

$$
\frac{\partial U}{\partial C_{a, t}^{i}}=\frac{1}{p_{t}^{H}} \beta E_{t}\left[\frac{\partial U}{\partial C_{a+1, t+1}^{i}}\left(\frac{\frac{\partial U}{\partial H_{a+1, t+1}^{i}}}{\frac{\partial U}{\partial C_{a+1, t+1}^{i}}}+p_{t+1}^{H}\left(1-\delta_{H}\right)\right)\right],
$$

implying that each individual's housing return is given by $\frac{\partial U / \partial H_{a+1, t+1}^{i}}{\partial U_{t+1} / \partial C_{a+1, t+1}^{i}}+p_{t+1}^{H}\left(1-\delta_{H}\right)$ where $\frac{\partial U / \partial H_{a+1, t+1}^{i}}{\partial U_{t+1} / \partial C_{a+1, t+1}^{i}}$ is the implicit rental price for housing services, referred to hereafter as "rent." For the national housing return, our return on a national housing index, we define national rent, $\mathcal{R}_{t+1}$, as the average of $\frac{\partial U / \partial H_{a+1, t+1}^{i}}{\partial U_{t+1} / \partial C_{a+1, t+1}^{i}}$ across individuals. Given this definition of national rent, we define the corresponding national housing return as

$$
\begin{aligned}
R_{H, t+1} & \equiv \frac{p_{t+1}^{H}\left(1-\delta_{H}\right)+\mathcal{R}_{t+1}}{p_{t}^{H}} \\
\mathcal{R}_{t+1} & \equiv \int_{\mathcal{S}} \frac{\partial U / \partial H_{a+1, t+1}^{i}}{\partial U_{t+1} / \partial C_{a+1, t+1}^{i}} d \mu
\end{aligned}
$$

In the model, $p_{t}^{H}$ is the price of a unit of housing stock, which holds fixed the composition of housing (quality, square footage, etc.) over time.

The risky capital return $R_{K, t}$ in (3) is the return on a value-weighted portfolio of risky capital. This is not the same as the empirical return on equity, which is a levered claim on risky capital. To obtain an equity return in the model, $R_{E, t}$, the return on assets, $R_{K, t}$, must be adjusted for leverage:

$$
R_{E, t} \equiv R_{f, t}+(1+B / E)\left(R_{K, t}-R_{f, t}\right),
$$

where $B / E$ is the fixed debt-equity ratio and where $R_{K, t}$ is the portfolio return for risky capital given in (3). ${ }^{13}$ Note that this calculation explicitly assumes that corporate debt in the model is exogenous, and held in fixed proportion to the value of the firm. (There is no financing decision.) For the results reported below, we set $B / E=2 / 3$ to match aggregate debt-equity ratios computed in Benninga and Protopapadakis (1990).

Euler equation for the risky asset return is satisfied. These results also imply that the equilibrium allocations of such economies are the same as the allocations obtained in otherwise identical economies with "static" firms that rent capital from households on a period-by-period basis. Although these conclusions have been formally proven only in an environment without adjustment costs, the magnitude of adjustment costs in our economy is calibrated to be very small, amounting to less than one percent of investment per year.

${ }^{13}$ The cost of capital $R_{K}$ is a portfolio weighted average of the return on debt $R_{f}$ and the return on equity $R_{e}: R_{K}=a R_{f}+(1-a) R_{e}$, where $a \equiv \frac{B}{B+E}$. 


\subsection{Equilibrium}

An equilibrium is defined as a set of prices (bond prices, wages, risky asset returns, house price, and land price) given by time-invariant functions $q_{t}=q\left(\mu_{t}, Z_{t}\right), \mathcal{W}_{t}=\mathcal{W}\left(\mu_{t}, Z_{t}\right)$, $R_{K, t}=R_{K}\left(\mu_{t}, Z_{t}\right), p_{t}^{H}=p^{H}\left(\mu_{t}, Z_{t}\right)$, and $p_{t}^{L}=p_{t}^{L}\left(\mu_{t}, Z_{t}\right)$, respectively, a set of cohortspecific value functions and decision rules for each individual $i,\left\{V_{a}, H_{a+1, t+1}^{i}, \theta_{a+1, t+1}^{i} B_{a+1, t+1}^{i}\right\}_{a=1}^{A}$ and a law of motion for $\mu, \mu_{t+1}=\Gamma\left(\mu_{t}, Z_{t}, Z_{t+1}\right)$ such that:

1. Households optimize:

$$
\begin{aligned}
v_{a}\left(\mu_{t}, Z_{t}, Z_{a, t}^{i}, W_{a, t}^{i}, H_{a, t}^{i}\right)= & \max _{H_{a+1, t+1}^{i} \theta_{a+1, t+1}^{i} B_{a+1, t+1}^{i}}\left\{U\left(C_{a, t}^{i}, H_{a, t}^{i}\right)\right. \\
& \left.+\beta \pi_{a+1 \mid a} E_{t}\left[V_{a+1}\left(\mu_{t+1}, Z_{t+1}, Z_{a, t+1}^{i}, W_{a+1, t+1}^{i}, H_{a+1, t+1}^{i}\right)\right]\right\}
\end{aligned}
$$

subject to (6), (7), (8), and (9) if the individual of working age, and subject to (7) and the analogous versions of (6), (8), and (9) (using pension income in place of wage income), if the individual is retired.

2. Firm's maximize value: $V_{C, t}$ solves (1), $V_{H, t}$ solves (2).

3. The land/permits price $p_{t}^{L}$ satisfies $p_{t}^{L}=(1-\phi) p_{t}^{H} Z_{H, t} \mathcal{L}_{t}^{-\phi}\left(K_{H, t}^{\nu} N_{H, t}^{-\nu}\right)^{\phi}$.

4. The land/permits market clears: $\overline{\mathcal{L}}=\mathcal{L}_{t}$.

5. Wages $\mathcal{W}_{t}=\mathcal{W}\left(\mu_{t}, Z_{t}\right)$ satisfy

$$
\begin{aligned}
& \mathcal{W}_{t}=(1-\alpha) Z_{C, t} K_{C, t}^{\alpha} N_{C, t}^{-\alpha} \\
& \mathcal{W}_{t}=(1-\nu)(1-\phi) p_{t}^{H} Z_{H, t} \mathcal{L}_{t}^{\phi} K_{H, t}^{\nu(1-\phi)} N_{H, t}^{-\phi(1-\nu)-\nu} .
\end{aligned}
$$

6. The housing market clears: $p_{t}^{H}=p^{H}\left(\mu_{t}, Z_{t}\right)$ is such that

$$
Y_{H, t}=\int_{\mathcal{S}}\left(H_{a, t+1}^{i}-H_{a, t}^{i}\left(1-\delta_{H}\right)\right) d \mu .
$$

7. The bond market clears: $q_{t}=q\left(\mu_{t}, Z_{t}\right)$ is such that

$$
\int_{\mathcal{S}} B_{a, t}^{i} d \mu+B_{F, t}=0
$$

8. The risky asset market clears: $R_{K, t}=R_{K}\left(\mu_{t}, Z_{t}\right)$ is such that

$$
1=\int_{\mathcal{S}} \theta_{a, t}^{i} d \mu
$$


9. The labor market clears:

$$
N_{t} \equiv N_{C, t}+N_{H, t}=\int_{\mathcal{S}} L_{a, t}^{i} d \mu
$$

10. The social security tax rate is set so that total taxes equal total retirement benefits:

$$
\tau N_{t} \mathcal{W}_{t}=\int_{\mathcal{S}} P E_{a, t}^{i} d \mu
$$

11. Government revenue from land/permit rentals equals total government spending, $G_{t}$ :

$$
p_{t}^{L} \mathcal{L}_{t}=G_{t}
$$

12. The presumed law of motion for the state space $\mu_{t+1}=\Gamma\left(\mu_{t}, Z_{t}, Z_{t+1}\right)$ is consistent with individual behavior.

Equations (17), (18) and (22) determine the $N_{C, t}$ and therefore determine the allocation of labor across sectors:

$$
(1-\alpha) Z_{C, t} K_{C, t}^{\alpha} N_{C, t}^{-\alpha}=(1-\nu)(1-\phi) p_{t}^{H} Z_{H, t} \mathcal{L}_{t}^{\phi} K_{H, t}^{\nu(1-\phi)}\left(N_{t}-N_{C, t}\right)^{-\phi(1-\nu)-\nu}
$$

Also, the aggregate resource constraint for the economy must take into account the housing and risky capital market transactions/participation costs and the wasteful government spending, which reduce consumption, the adjustment costs in productive capital, which reduce firm profits, and the change in net foreign capital in the bond market, which finances domestic consumption and investment. Thus, non-housing output equals non-housing consumption (inclusive of costs $F_{t}$ ) plus government spending plus aggregate investment (gross of adjustment costs) less the net change in the value of foreign holdings:

$$
\begin{aligned}
Y_{C, t}=C_{t}+F_{t}+G_{t}+\left(I_{C, t}\right. & \left.+\phi_{C}\left(\frac{I_{C, t}}{K_{C, t}}\right) K_{C, t}\right)+\left(I_{H, t}+\phi_{H}\left(\frac{I_{H, t}}{K_{H, t}}\right) K_{H, t}\right) \\
& \underbrace{-\left(B_{t+1}^{F} q\left(\mu_{t}, Z_{t}\right)-B_{t}^{F}\right)}_{\text {trade balance }},
\end{aligned}
$$

where $C_{t}$ and $F_{t}$ are aggregate quantities defined as ${ }^{14}$

$$
C_{t} \equiv \int_{\mathcal{S}} C_{a, t}^{i} d \mu \quad F_{t} \equiv \int_{\mathcal{S}} F_{t}^{i} d \mu .
$$

\footnotetext{
${ }^{14}$ Note that (25) simply results from aggregating the budget constraints across all households, imposing all market clearing conditions, and using the definitions of dividends as equal to firm revenue minus costs.
} 
The term labeled "trade balance" is equal to the current account less net financial income from abroad, i.e., current account $=$ trade balance $-\frac{B_{t+1}^{F}}{q\left(\mu_{t}, Z_{t}\right)}$. Note that debt service is $\frac{B_{t+1}^{F}}{q\left(\mu_{t}, Z_{t}\right)}$.

To solve the model, it is necessary to approximate the infinite dimensional object $\mu$ with a finite dimensional object. The appendix explains the solution procedure and how we specify a finite dimensional vector to represent the law of motion for $\mu$. The resulting approximation, or "bounded rationality" equilibrium has been used extensively in the literature to solve incomplete markets models (see the appendix for further discussion).

\subsection{Welfare Measure}

To quantify the welfare effects of different foreign holdings regimes, we use a consumption equivalent variation measure. To explain this measure, it is necessary to introduce some additional notation. Let $H_{t}$ denote aggregate housing wealth, i.e., $H_{t} \equiv \int_{\mathcal{S}} H_{a, t}^{i} d \mu$, and analogously for other individual variables. To study a growing economy, it will be convenient to normalize trending variables by trend output and denote their deterministically detrended values in lower case, e.g., $z_{c, t} \equiv Z_{c, t} \exp (-g t), h_{t}^{i} \equiv H_{t}^{i} \exp (-g t)$, etc. The solved policy functions and state variables are expressed in terms of normalized variables.

Recall that the aggregate state of the economy is a pair, $\left(Z_{t}, \mu_{t}\right)$, where $Z_{t} \equiv\left(z_{C, t}, z_{H, t}, b_{F, t}, b_{F, t+1}\right)^{\prime}$ denotes the exogenous aggregate states and $\mu_{t}$ is a measure defined over

$$
\mathcal{S}=(\mathcal{A} \times \mathcal{Z} \times \chi \times \mathcal{H})
$$

As explained in the appendix, the bounded rationality equilibrium is computed by approximating the infinite dimensional object $\left(Z_{t}, \mu_{t}\right)$ with a finite dimensional vector of aggregate state variables. Let the subset of aggregate state variables excluding foreign bonds be approximated by $\mu_{t}^{A G}$ :

$$
\left(z_{C, t}, z_{H, t}, \mu_{t}\right) \approx \mu_{t}^{A G}=\left(z_{C, t}, z_{H, t}, k_{C, t}, \frac{k_{C, t}}{k_{C, t}+k_{H, t}}, h_{t}, p_{t}^{H}, q_{t}\right) .
$$

We may write the household value function as a function of detrended variables as

$$
v_{a}\left(\mu_{t}^{A G}, b_{F, t}, b_{F, t+1}, Z_{t}^{i}, w_{t}^{i}, h_{t}^{i}\right)
$$

Integrating out aggregate risk except foreign bonds we have

$$
\bar{v}_{a}\left(b_{F, t}, b_{F, t+1}, Z_{t}^{i}, w_{t}^{i}, h_{t}^{i}\right)=\int v_{a}\left(\mu_{t}^{A G}, b_{F, t}, b_{F, t+1}, Z_{t}^{i}, w_{t}^{i}, h_{t}^{i}\right) d \mu_{t}^{A G} .
$$

We quantify the welfare consequences of different foreign capital states by computing the increment to lifetime utility, (the household value function) in units of the composite 
(housing plus nonhousing) consumption good, of being in a high versus low state of foreign capital holdings relative to trend GDP. We call this a consumption "equivalent variation" $(\mathrm{EV})$ measure. For example, we can compute the equivalent variation measure for individual $i$ of age $a$ that would result from transitioning into a different foreign capital state at $t+1$ by an increment $\Delta$, compared to remaining in a particular foreign capital state $b_{F, t+1}=b_{F, t}$ :

$$
E V_{i, a}=\left(\frac{\bar{v}_{a}\left(b_{F, t}, b_{F, t}+\Delta, Z_{t}^{i}, w_{t}^{i}, h_{t}^{i}\right)}{\bar{v}_{a}\left(b_{F, t}, b_{F, t}, Z_{t}^{i}, w_{t}^{i}, h_{t}^{i}\right)}\right)^{\frac{\sigma}{\sigma-1}}-1 .
$$

The equivalent variation measure tells us how much this individual's lifetime composite consumption must be increased so that her lifetime utility from remaining in a particular foreign capital state $b_{F, t}$ equals that from transitioning to $b_{F, t}+\Delta$. (We multiply the units by 100 so as to express them in percent.) Positive numbers therefore reflect a welfare gain from transitioning, whereas negative numbers reflect a welfare loss.

We use a similar criterion to compute an ex-ante welfare measure under the "veil of ignorance." That is, we compute the welfare implications of a change in foreign holdings for an agent about to be born (age $=0)$ with no financial wealth and the average (across agents and over time) idiosyncratic productivity, $Z_{t}^{i}=1$. This is computed using that agent's value function at the start of life, which takes incorporates the agent's expectation of lifetime utility over all possible aggregate and idiosyncratic shocks in the future, i.e.,

$$
E V_{N B}=\left(\frac{\bar{v}_{1}\left(b_{F, t}, b_{F, t}+\Delta, 1,0, h_{0}\right)}{\bar{v}_{1}\left(b_{F, t}, b_{F, t}, 1,0, h_{0}\right)}\right)^{\frac{\sigma}{\sigma-1}}-1,
$$

where all individuals start life with zero financial wealth and the same, very small, amount, $h_{0}$, of housing wealth. ${ }^{15}$

Finally, we compare the welfare consequences for more aggregated demographic groups in a similar manner, integrating over $E V$ across such groups. For example, we may compute the welfare consequences for young households (age less than 35) as

$$
E V_{i, a \leq 35}=\int_{a \leq 35}\left(\frac{\bar{v}_{a}\left(b_{F, t}, b_{F, t}+\Delta, Z_{t}^{i}, w_{t}^{i}, h_{t}^{i}\right)}{\bar{v}_{a}\left(b_{F, t}, b_{F, t}, Z_{t}^{i}, w_{t}^{i}, h_{t}^{i}\right)}\right)^{\frac{\sigma}{\sigma-1}} d a-1 .
$$

We form analogous measures for other age groups and for groups distinguished by wealth and income.

Note that the welfare measures above take the average of the ratio of the value functions. An alternative would be to take the ratio of the average. In practice the latter approach is

\footnotetext{
${ }^{15}$ Housing wealth cannot be zero or utility is infinite. Therefore, all individuals are assumed to start life with the amount of housing equal to the lowest point on the housing grid.
} 
a problem because the ratio of averages is highly sensitive to a few outliers in the wealth distribution, usually one extremely poor household. In this case, that household's utility dominates the average utility and the welfare comparison becomes a comparison of tails of the wealth distribution.

The integrals are computed as averages from a very long simulated sample path. We locate all dates in this path for which $b_{F, t}$ is equal to a particular value $\widetilde{b}$, and for which $b_{F, t+1}$ is equal to $\widetilde{b}+\Delta$, and then locate all dates in which $b_{F, t}=b_{F, t+1}=\widetilde{b}^{16}$ We then form the ratio $\bar{v}_{a}\left(\widetilde{b}, \widetilde{b}+\Delta, Z_{t}^{i}, w_{t}^{i}, h_{t}^{i}\right) / \bar{v}_{a}\left(\widetilde{b}, \widetilde{b}, Z_{t}^{i}, w_{t}^{i}, h_{t}^{i}\right)$ and average this ratio over the relevant subgroup of the population. We set the increment, $\Delta$, equal to a typical increase or decrease in foreign holdings given the stochastic process (10), i.e., $\Delta=\left(1-\rho_{F}\right) \bar{b}+\rho_{F} b_{F, t}+\sigma_{F} \cdot 1$ (increase) or $\Delta=\left(1-\rho_{F}\right) \bar{b}+\rho_{F} b_{F, t}+\sigma_{F} \cdot(-1)$ (decrease).

\subsection{Model Calibration}

The model's parameters and their numerical calibration are reported in Table 1. A detailed explanation of this calibration is given in the Appendix. The technology shocks $Z_{C}$ and $Z_{H}$ are assumed to follow two-state independent Markov chains; the calibration is described in the Appendix. The Appendix also describes our calibration of the individual productivity shocks. Both the numerical grid and the parameters of the $\mathrm{AR}(1)$ process for $b_{F, t+1}(10)$ are calibrated from historical data on foreign holdings of U.S. Treasury debt spanning the period 1984 to 2010. A detailed explanation is given in the Appendix. This leads to values for $\rho_{b}=0.95, \bar{b}=0.148$, and $\sigma_{b}=0.0171$.

\section{Results}

This section presents the model's main implications. Unless otherwise noted, these implications are based on long simulations of the model using the solved optimal policy functions and evolution equations for the state variables. Before turning to the welfare implications of changes in foreign holdings, we present the model's predictions for a set of benchmark business cycle statistics and asset pricing statistics.

\footnotetext{
${ }^{16}$ In practice, this is accomplished by locating all points within a close radius of a particular value.
} 


\subsection{Business Cycle Moments}

Table 2 presents benchmark results for Hodrick-Prescott (Hodrick and Prescott (1997)) detrended aggregate quantities. Panel A presents business cycle moments from U.S. annual data over the period 1953 to 2010. Panel B presents simulated data from the model. We report statistics for total output, or $G D P \equiv Y=Y_{C}+p^{H} Y_{H}+C_{H}$, for non-housing consumption (inclusive of expenditures on financial services), equal to $C_{t}+F_{t}$, for housing consumption $C_{H, t}$, defined as price per unit of housing services times quantity of housing or $C_{H, t} \equiv \mathcal{R}_{t} H_{t}$, for total (housing and non-housing) consumption $C_{T, t}=C_{t}+F_{t}+C_{H, t}$, for non-housing investment (inclusive of adjustment costs) $I_{t}=\left(I_{C, t}+\phi_{C}(\cdot) K_{C, t}\right)+\left(I_{H, t}+\phi_{H}(\cdot) K_{H, t}\right)$, for residential investment, $p_{t}^{H} Y_{H, t}$, and for total investment $I_{T, t}=I_{t}+p_{t}^{H} Y_{H, t}$.

The standard deviation of total aggregate consumption divided by the standard deviation of GDP is 0.77 in the model, close to the 0.74 value found in the data. In addition, the level of GDP volatility in the model is close to that in the data. Thus the model produces a plausible amount of aggregate consumption volatility. Total investment is more volatile than output, both in the model and in the data, and the model produces about the right amount of relative volatility: the ratio of the standard deviation of total investment to that of GDP is 3.2 in the model compared to 3.5 in the data. The model does a good job of matching the relative volatility of residential investment to output: in the data the ratio of these volatilities is 5.6, while it is 4.9 in the model. Finally, both in the model and the data, residential investment is less correlated with output than is consumption and total investment. The model somewhat understates the share of consumption in GDP.

To get a sense of the how aggregate business cycle statistics are affected by the quantities of foreign holdings of domestic assets, as well as by a capital inflow (outflow), Table 3 presents the mean and standard deviation of the (detrended) aggregate variables, conditional on the level (stock) of foreign holdings as of last period, $b_{F, t}$ (external leverage), as well as on the change (flow) in foreign holdings this period, $\Delta b_{F, t+1}$. The statistics are reported conditional on being in the top or bottom half of the sample in terms of these variables, distinguished as high, "H" or low, "L" in Table 3.

A capital inflow, which represents a negative trade balance or a current account deficit, finances domestic spending and therefore acts like a positive economic shock. Table 3 shows that a high capital inflow stimulates investment and consumption: the means of these variables are higher when capital inflows are high than when inflows are low. On the other hand, a high stock of external leverage, $b_{F, t}$, has little impact on consumption and investment. The stimulatory affect of past inflows is dampened by the expectation that the debt must eventu- 
ally be repaid, as capital flows relative to GDP slowly mean-revert. A high capital inflow also makes consumption more volatile but investment less volatile, relative to low capital inflow states. This occurs because foreign purchases of the riskless bond crowd domestic savers out of the safe bond market, reducing the availability of one of the assets used to insure against aggregate risk. The result is a rise in aggregate consumption volatility. Investment volatility, on the other hand, falls because a high inflow simultaneously leads to a higher level of investment. With convex adjustment costs, the volatility of investment is reduced because the cost of any given change in investment is higher when the level of investment is high.

How do the stock and flow in external leverage affect growth rates of aggregate variables? Table 4 shows the sensitivity of the log difference in aggregate variables to both the level of external holdings last period, $b_{F, t}$, and the capital flow $\Delta b_{F, t}$, from a multivariate regression on these variables. A capital inflow $\Delta b_{F, t+1}$ stimulates higher economic growth (consumption, investment and GDP), and higher growth in the capital stocks at the beginning of next period (housing and physical capital). The marginal effect of a high capital inflow also raises the real wage (row 10), since the influx of foreign funds stimulates growth in the capital stock and, along with it, the value of the relatively scarce factor (labor). Once one controls for the stimulatory impact of a higher capital inflow, however, a high level of external debt has a small contractionary effect on spending (consumption and investment) and GDP, since the higher debt must eventually be repaid. In contrast to the effects of a capital inflow, however, the affects of these changes in the stock of external debt on investment are too small to have a discernable influence on the slow-moving physical and housing capital stocks.

\subsection{Asset Pricing Implications of International Capital Flows}

Table 5 reports the model's implications for asset pricing moments. The table reports unconditional moments in the "all" column, as well as moments conditional on either the stock of foreign holdings last period, $b_{F, t}$, or on the flow this period, $\Delta b_{F, t+1}$. These conditional moments are calculated conditional on the observation being in either the top or bottom half of the sample in terms of $b_{F, t}$ or $\Delta b_{F, t+1}$. The Sharpe ratio for each asset, denoted $S R[\cdot]$, is defined to be the mean of the return on the asset in excess of the risk-free rate, divided by the standard deviation of this excess return.

The benchmark model matches the historical mean return for the risk-free rate but somewhat overstates the volatility of the risk-free rate. The model produces a sizable equity return 
of about $6 \%$ per annum (an annual equity premium of 4.5\%) and an annual Sharpe ratio of 0.51 . Two factors related to the cyclicality of the cross-sectional distribution of consumption contribute to the model's high average risk premium and Sharpe ratio. First, idiosyncratic income risk is countercyclical. Second, house prices and therefore collateral values are procyclical, making borrowing constraints countercyclical. These factors mean that insurance/risk-sharing opportunities are reduced precisely when households need them most (in recessions) resulting in a high risk premium and Sharpe ratio.

One shortcoming of the present setup is that the volatility of the equity return is just a bit more than half of what it is in post-war data. This reflects a well known trade-off in production-based models with adjustment costs between matching the volatility of investment and the volatility of equity returns. Higher adjustment costs lead to a more volatile equity return but less volatile investment. One potential resolution is to increase adjustment costs while at the same time introducing additional shocks to offset the reduction in the volatility of investment, such as e.g., stochastic depreciation in capital, as in Storesletten, Telmer, and Yaron (2007) and Gomes and Michaelides (2008), or investment-specific technology shocks. We do not pursue these possibilities here in order to keep the complexity of the model to a minimum and the numerical solution procedure manageable.

For housing assets, Table 5 shows that the model produces about the right mean return and excess return for the aggregate house price index. The mean excess housing return is $9.72 \%$ on an annual basis, with Sharpe ratio equal to 1.81 , .comparable to U.S. data for aggregate house price indexes. It is important to note that the housing Sharpe ratio as defined here, both in the model and the data, is not a Sharpe ratio for an individual house. Thus it is not the Sharpe ratio of a feasible trading strategy, since it pertains to an aggregate house index return. Individual houses are subject to significant idiosyncratic risk that is averaged out in the aggregate index. It follows that the standard deviation of the aggregate housing return is much lower, and its Sharpe ratio much higher, than the corresponding figures for a typical individual home.

The right-most four columns of Table 5 show asset pricing moments conditional on the amount of external leverage, $b_{F, t}$, or conditional on high or low capital inflows, $\Delta b_{F, t+1}$. A high capital inflow leads to a sharp decline in the riskless interest rate and in the expected returns on equity and housing. At the same time, however, a capital inflow leads to an increase in equity and housing risk premia and Sharpe ratios. The Sharpe ratio on equity is $42 \%$ higher in high capital inflow states than in low capital inflow states. Risk premia rise because the inflow reduces the effective supply of the safe asset, forcing domestic savers 
to hold more of their funds in the form of risky securities. Thus, although total expected returns (discount rates) fall in response to a capital inflow, the risk-premium component of the discount rate rises. The rise in risk premia in turn partially (but not fully) offsets the stimulatory impact of a lower riskless interest rate on home prices, a result previously emphasized in FLVN, partly explaining why there is only a modest increase in the pricerent ratio in response to a capital inflow (row 13). (The aggregate home price increase is also limited by the equilibrium increase in residential investment, as discussed below.) Row 6 shows that a capital inflow reduces the volatility of stock returns because, as discussed above, both the level of investment and therefore the adjustment costs are higher in those states, and the volatility of investment lower. Since both investment and the stock price are linked through the marginal value of an additional unit of capital (marginal $q$ ), stock return volatility falls along with investment volatility.

In contrast to the modest impact a foreign capital inflow has on the price-rent ratio, row 14 of Table 4 shows that the stock price-dividend ratio responds sharply to a capital inflow and is $44 \%$ higher than average, conditional on a capital inflow, and the same amount lower conditional on a capital outflow. This occurs because a capital inflow is met with a significant increase in expected dividend growth that is not present for expected rent growth. Indeed, as emphasized in FLVN, positive economic shocks are associated with an expectation of lower future rental growth because they stimulate residential investment. ${ }^{17}$ As residential investment expands, the cost of future housing services (rent) is expected to be lower, rather than higher, an effect that, by itself, would reduce the price-rent ratio. This isn't the only effect, however, and on balance the price-rent ratio still rises in response to a capital inflow because the decline in discount rates more than offsets the expected fall in future rent growth. ${ }^{18}$

Taken together, these elements of the model imply that a reserve-driven capital inflow of the type that occurred in the last 15 years can have, at most, a limited impact on home prices. This is evident from row 13 of Table 4, which shows that high capital inflow states

\footnotetext{
${ }^{17}$ Rents are inversely related to the housing stock because the implicit rental price for housing services is positively related the marginal utility of housing services relative to the marginal utility of non-housing services. Thus an expansion of the housing stock reduces the expected growth rate of future rents. By contrast, expected future profits of the productive sector are positively related to an expansion of the physical capital stock because the resulting increase in the marginal product of labor more than offsets the marginal cost of new investment.

${ }^{18}$ Predictable variation in housing returns must therefore account for more than 100 percent of the variability in price-rent ratios.
} 
lead to a relatively small (on the order of $2.4 \%$ ) increase in the price-rent ratio relative to the average across all states. This outcome occurs because both the rise in risk premia and the decline in expected future rent growth that accompany an inflow drag the price-rent ratio down at the same time as the lower riskless rate pushes it up. In the absence of these endogenous changes in risk premia and expected rent growth (as occurs, for example, in partial equilibrium analyses), a decline in the riskless interest rate on the order of magnitude generated by high versus low capital inflows (column 7 versus column 8, row 1) would lead to a very substantial increase in the price-rent ratio. The contrary finding here, namely that a large, reserve-driven decline in interest rates generates a relatively small increase in house prices, underscores the importance of general equilibrium considerations in the analysis of global capital markets. ${ }^{19}$

Table 5 (columns 5 and 6 ) also shows that a high level of external leverage, $b_{F, t}$, raises both the risk premium on equity and housing and the volatility of these assets, as domestic households on the whole are now in a more levered portfolio position. This outcome is the same as that in Caballero and Krishnamurthy (2009) (CK), who study a two-asset (equity and risk-free rate) representative agent exchange economy in which foreign demand for the safe asset is perfectly correlated with (but less volatile than), domestic consumption. That model, like this one, implies that high external leverage increase the equity risk premium. But unlike here, in their model a capital inflow (an increase in external leverage) lowers risk premia. The reasons for this difference are three-fold. First, capital flows in CK are assumed to be more stable than domestic cash flows, which lowers risk premia by stabilizing the economy. Here, capital flows are independent of the aggregate state and have innovations that are about as volatile as GDP. Second, unlike CK, international capital flows are not perfectly correlated with domestic cash flows; they therefore add systematic risk to the economy, uncorrelated with the aggregate risk already there. Third, CK solve their model in continuous time, so that the instantaneous effect of a capital inflow has a negligible effect on leverage. By contrast, in the discrete time setting here, capital inflows have an immediate effect on external leverage. Capital inflows here therefore influence the economy in much the same way that CK's level of external leverage does, which in their model becomes the dominant driver of the risk premium over time.

\footnotetext{
${ }^{19}$ It follows that other factors must be primarily responsible for the large boom-bust cycle in home prices that occurred from 2000-2010. Favilukis, Ludvigson, and Van Nieuwerburgh (2009) argue that plausibly calibrated changes in collateral requirements and housing transactions costs over this period can account for the run-up and subsequent decline in U.S. aggregate house price-rent ratios.
} 
Finally, we investigate how international capital flows affect the growth rates of asset values, returning to Table 4 . The last two rows of Table 4 show the sensitivity of the log difference in the value of the risky mutual fund formed from ownership claims to the two productive sectors (denoted $V_{t} \equiv V_{C, t}+V_{H, t}$ ), as well as housing wealth, $p_{t}^{H} H_{t+1}$, to both the level of external holdings last period, $b_{F, t}$, and the current capital flow $\Delta b_{F, t+1}$, from a multivariate regression on these variables. A capital inflow stimulates the aggregate value of the risky mutual fund as well as housing wealth, $p_{t}^{H} H_{t+1}$. But conditional on the inflow, the level of external finance depresses asset values as the financing burden of higher external debt takes its toll on domestic spending and ultimately on asset valuations.

\subsection{Welfare Implications}

With an understanding of how international capital flows are related in equilibrium to aggregate quantities and asset prices, we now turn to their welfare effects. The welfare consequences, by age, of a capital inflow or outflow are displayed in Figure 4, quantified by the EV measure discussed above. This equivalent variation measure tells us how much, in percent, this individual's lifetime composite consumption must be increased so that her lifetime utility from remaining in a particular foreign capital state $b_{F, t}$ equals that from transitioning to $b_{F, t}+\Delta$, where $\Delta$ is set to equal a typical change in foreign flows given our estimated standard deviation of the stochastic process (10), i.e.,: $\Delta=\left(1-\rho_{F}\right) \bar{b}+\rho_{F} b_{F, t}+\sigma_{F} \cdot 1$ (a typical increase in foreign flows) or $\Delta=\left(1-\rho_{F}\right) \bar{b}+\rho_{F} b_{F, t}+\sigma_{F} \cdot(-1)$ (a typical decrease). Notice that $\Delta$ depends on the level of external debt brought in from last period, $b_{F, t}$, as well as on whether $\eta_{t}=1$ or -1 . Figure 4 shows the EV measure integrated out across all values of $b_{F, t}$ (dashed lines), as well as conditional on the economy residing in particular quintiles of $b_{F, t}$ (solid lines). The consequences of a capital inflow are shown in the left panel and a capital outflow in the right panel.

Figure 4 shows that the welfare implications of a capital inflow or outflow are nonmonotone in age. A capital inflow benefits the young (age 35 or less), while an outflow is costly. The young benefit from a capital inflow due to lower interest rates, which reduce the costs of home ownership and of borrowing in anticipation of higher expected future income attributable to the hump-shaped life-cycle profile in earnings. In the lowest quintile of external leverage, the youngest households require $1 \%$ more lifetime consumption to make them as well off as they would be from transitioning to a higher $\Delta>0$ level of external leverage. Conversely, a capital outflow hurts the young; in the highest quintile of external 
leverage, the youngest households would be willing to give up approximately $1.5 \%$ of lifetime consumption in order to forgo transitioning to a lower $\Delta<0$ level of external leverage.

Figure 4 shows that middle-aged savers (age 45 to 75) are hurt by a capital inflow. This occurs for two reasons. First, they are crowded out of the safe bond market and exposed to greater systematic risk in equity and housing markets. Although they are partially compensated for this in equilibrium by higher risk-premia, they still suffer from a second effect of an inflow: lower expected rates of return on all assets, the riskless bond, equity, and housing. The net effect of these two means that middle-aged savers experience a welfare loss from an inflow and, conversely, a welfare gain from a capital outflow.

Older retired individuals, on the other hand, are far less hurt by either lower expected rates of return or by greater exposure to systematic risk. This is because they have fewer years to go until the end of life and are in a dissaving stage of the life-cycle. Moreover, because retirees earn a pension that is in large part determined by their earnings in the last period of working life, even those with considerable housing and equity wealth are less exposed to systematic risk than are individuals of working age, whose labor earnings vary not only with the current aggregate state but also with the countercyclical fluctuation in the variance of idiosyncratic earnings surprises-see (4). ${ }^{20}$ Taken together, these factors imply that older households experience a significant net gain from even modest increases in asset values that accompany a capital inflow. Conversely, from the highest external leverage quintile, the oldest individuals would be willing to forgo up to $1.6 \%$ of lifetime consumption to avoid a capital outflow and the resulting drop in asset prices.

How do the welfare implications vary by income and net worth? Figure 5 decomposes the welfare costs of a capital outflow by age, income and wealth. Significant heterogeneity by income and wealth is exhibited for young and old individuals, but not for the middleaged. Young individuals who are high-income or wealthy suffer less from a capital outflow than low-income or poor households because they are better equipped to self-insure against idiosyncratic and aggregate risks without the benefit of easier borrowing terms that foreign capital provides. Less affluent households must rely more on external finance in order to avoid bumping up against collateral constraints; they are therefore hurt more when external finance declines. For older individuals, the story is different. High net worth retirees suffer more than low net worth retirees, because they have the most to lose from an outflow, namely

\footnotetext{
${ }^{20}$ Pension (Social Security) income is not entirely insulated from aggregate risk, since the pay-as-you-go system depends on tax revenue, which in turn depends on the current wage. But it is still far less sensitive to the current aggregate state than is labor income.
} 
a decline in the value of their assets. The same pattern occurs when comparing high versus low income retirees because income and net worth are positively correlated.

Finally, Figure 6 shows the welfare costs of a capital outflow under the "veil of ignorance" to agents just being born, as computed using (28). The measure compares the value function of a newborn, born into the fifth quintile of today's foreign holdings, $b_{F, t+1}=b_{5, t+1}$, with the value function of a newborn born into each of the other quintiles, $b_{F, t+1}=b_{1, t+1}$, $b_{2, t+1}, \ldots, b_{4, t+1}$, for various levels of last period's holdings $b_{F, t}$. The comparison is between two newborns with the same initial financial wealth (zero), the same initial housing wealth, and the average (across agents and over time) idiosyncratic productivity draw, $Z_{t}^{i}=1$. Figure 6 shows that newborns born into high capital inflow states are better off than those born into low capital inflow states. The expected welfare losses from the outflow that will occur when they are middle-aged savers are more than offset by the expected benefits when they are young and elderly. The largest differences in welfare, quantitatively, come from comparing an individual born into the fifth quintile with one born into the first quintile of current foreign holdings: the individual born into the fifth quintile would be willing to forgo up to $1 \%$ of lifetime consumption in order to avoid being born into the first quintile.

\section{Conclusion}

The last two decades have been marked by a steady rise in international ownership of U.S. assets considered to be safe stores-of-value. Some have argued that these trends are optimal or benign, and/or that countries like the United States ultimately benefit from easier borrowing terms (e.g., Dooley, Folkerts-Landau, and Garber (2005), Cooper (2007), Mendoza, Quadrini, and Rios-Rull (2007), Caballero, Fahri, and Gourinchas (2008a)). Others (sometimes at the same time) have warned of the hazards of ever-increasing external leverage, and of the greater systematic risk that accompanies it (Caballero, Fahri, and Gourinchas (2008a), Caballero, Fahri, and Gourinchas (2008b), Obstfeld and Rogoff (2009), Fahri, Gourinchas, and Rey (2011)). Missing from this analysis are general equilibrium models of aggregate and idiosyncratic risks, plausible financial markets, and household heterogeneity with which to study the welfare consequences of these global capital flows.

In this paper, we turn to such a general equilibrium theory in order better our understanding of the distributional consequences of this brand of international capital flow. We find that these flows confer on U.S. households both costs and benefits, both greater risk and greater opportunities to insure against risk, and that they do so concurrently. The relevant 
question is, which households are privy to the benefits and which are subject to the costs?

The model we study implies that foreign governmental demand for U.S. safe assets does lead to easier borrowing terms in the U.S., which benefits young households who are in a borrowing stage of the life-cycle. It also benefits the wealthy old, both because they gain from the rise in asset values that accompanies a capital inflow, and because they have the least to lose from lower expected rates of return and from the greater exposure of domestic saving to systematic risk. On the other hand, such flows are costly for the middle-aged, who find their retirement savings earning lower expected rates of return on portfolios increasingly tilted towards assets with greater systematic risk. This phenomenon is reflected in a sharp rise in the equilibrium risk premium on equity and housing assets, and in a decline in the lifetime utility of households saving for retirement.

It is commonly believed that a large influx of international capital (on the order of magnitude experienced in the U.S. over the last 15 years) must play an important role in domestic home price appreciation. If so, one might expect that middle-aged savers who own homes would be likely to gain, rather than lose, from a capital inflow. This reasoning ignores the general equilibrium response of both residential investment and risk-premia to a capital inflow. A capital inflow acts like a positive economic shock, provoking a rise in residential investment, thereby reducing the expected growth rate of the dividend that housing pays. At the same time, a capital inflow causes an increase in the housing risk premium, implying that discount rates fall far less than the decline in the risk-free rate alone. Both of these factors work to offset the stimulatory impact of a capital inflow-driven decline in interest rates on home prices, thereby limiting a potential source of welfare gains to middle-aged homeowners. Of course, these same factors limit house price appreciation for all homeowners, including older homeowners who ultimately benefit from the capital inflow. The difference is that older households don't bear as much systematic risk in their retirement earnings as workers do in their labor earnings, and they suffer far less than those still accumulating wealth for retirement from lower expected rates of return.

In closing, we note that purchases of long-term Treasuries by the U.S. Federal Reserve, such as those that occurred in 2010 and 2011 in their so-called quantitative easing "QE2" initiatives, are likely to have effects that are similar to those resulting from purchases of these same securities by foreign governmental holders. Importantly, the Federal Reserve's demand for U.S. Treasuries, like those of foreign governmental holders, is likely to be extremely price inelastic as it pursues specific monetary policy goals that do not play a role in private demand for such securities. A complete analysis of the distributional consequences of these 
and related policy programs is an important topic for future study. 


\section{Appendix}

This appendix describes how we calibrate the stochastic shock processes in the model, describes the historical data we use to measure house price-rent ratios and returns, and describes our numerical solution strategy.

\subsection{Calibration of Stochastic Process for $b_{F, t}$}

Individuals in the model form beliefs about the evolution of the stochastic process for foreign holdings relative to trend GDP, $b_{F, t}=B_{F, t} / \bar{Y}_{t}$. We assume these beliefs take the form given in (10) and calibrate parameters of this process from U.S. data. In the data, $\bar{Y}_{t}$ is trend GDP as computed from a Hodrick-Prescott filter (Hodrick and Prescott (1997)). The historical data on $B_{F, t}$ consist of 13 observations between December 1984 and June 2010, irregularly spaced, on foreign ownership of U.S. Treasury debt (T-bonds and T-notes). The source for these data is Department of the Treasury, Treasury International Capital System division. The numerical grid is set to match the span of observations on $b_{F, t}$. We obtain an annual time series from the raw data by fitting a Hermite polynomial through the raw data, respecting the exact date of each observation. This delivers a time series of 27 annual observations from 1984 until 2010. An AR(1) is then estimated through these observations. This leads to the parameter combination, $\rho_{F}=0.968, \bar{b}=0.1475$, and $\sigma_{F}=0.0171$. We use a value for the persistence parameter, $\rho_{F}=0.95$, that is slightly lower than the point estimate since it delivers more stable numerical results. The innovation $\eta_{t+1}$ is assumed to take on two values with equal probability: $\eta=[1,-1]$.

\section{Calibration of Shocks}

The aggregate technology shock processes $Z_{C}$ and $Z_{H}$ are calibrated following a two-state Markov chain, with two possible values for each shock, $\left\{Z_{C}=Z_{C l}, Z_{C}=Z_{C h}\right\}$, $\left\{Z_{H}=Z_{H l}, Z_{H}=Z_{H h}\right\}$, implying four possible combinations:

$$
\begin{aligned}
Z_{C}=Z_{C l,} & Z_{H}=Z_{H l} \\
Z_{C}=Z_{C h,} & Z_{H}=Z_{H l} \\
Z_{C}=Z_{C l,} & Z_{H}=Z_{H h} \\
Z_{C}=Z_{C h,} & Z_{H}=Z_{H h .}
\end{aligned}
$$


Each shock is modeled as,

$$
\begin{aligned}
& Z_{C l}=1-e_{C}, \quad Z_{C h}=1+e_{C} \\
& Z_{H l}=1-e_{H}, \quad Z_{C h}=1+e_{H},
\end{aligned}
$$

where $e_{C}$ and $e_{H}$ are calibrated to match the volatilities of GDP and residential investment in the data.

We assume that $Z_{C}$ and $Z_{H}$ are independent of one another. Let $\mathbf{P}^{C}$ be the transition matrix for $Z_{C}$ and $\mathbf{P}^{H}$ be the transition matrix for $Z_{H}$. The full transition matrix equals

$$
\mathbf{P}=\left[\begin{array}{cc}
p_{l l}^{H} \mathbf{P}^{C} & p_{l h}^{H} \mathbf{P}^{C} \\
p_{h l}^{H} \mathbf{P}^{C} & p_{h h}^{H} \mathbf{P}^{C}
\end{array}\right]
$$

where

$$
\mathbf{P}^{H}=\left[\begin{array}{cc}
p_{l l}^{H} & p_{l h}^{H} \\
p_{h l}^{H} & p_{h h}^{H}
\end{array}\right]=\left[\begin{array}{cc}
p_{l l}^{H} & 1-p_{l l}^{H} \\
1-p_{h h}^{H} & p_{h h}^{H}
\end{array}\right],
$$

and where we assume $\mathbf{P}^{C}$, defined analogously, equals $\mathbf{P}^{H}$. We calibrate values for the matrices as

$$
\begin{aligned}
\mathbf{P}^{C}= & {\left[\begin{array}{ll}
.60 & .40 \\
.25 & .75
\end{array}\right] } \\
\mathbf{P}^{H}= & {\left[\begin{array}{ll}
.60 & .40 \\
.25 & .75
\end{array}\right]=>} \\
\mathbf{P}= & {\left[\begin{array}{llll}
.36 & .24 & .24 & .16 \\
.15 & .45 & .10 & .30 \\
.15 & .10 & .45 & .30 \\
.0625 & .1875 & .1875 & .5625
\end{array}\right] }
\end{aligned}
$$

With these parameter values, we match the average length of expansions divided by the average length of recessions (equal to 5.7 in NBER data from over the period 1945-2001). We define a recession as the event $\left\{Z_{C l}, Z_{H l},\right\}$, so that the probability of staying in a recession is $p_{l l}^{H} p_{l l}^{C}=0.36$, implying that a recession persists on average for $1 /(1-.36)=1.56$ years. We define an expansion as either the event $\left\{Z_{C h}, Z_{H l}\right\}$ or $\left\{Z_{C l}, Z_{H h}\right\}$ or $\left\{Z_{C h}, Z_{H h}\right\}$. Thus, there are four possible states (one recession, three expansion). The average amount of time spent in each state is given by the stationary distribution $(4 \times 1)$ vector $\boldsymbol{\pi}$, where

$$
\mathrm{P} \pi=\pi
$$


That is, $\boldsymbol{\pi}$ is the eigenvector for $\mathbf{P}$ with corresponding eigenvalue equal to 1 . The first element of $\boldsymbol{\pi}$, denoted $\pi_{1}$, multiplies the probabilities in $\mathbf{P}$ for transitioning to any of the four states tomorrow conditional on being in a recession state today. $\pi_{1}$ therefore gives the average amount of time spent in the recession state, while $\pi_{2}, \pi_{3}$, and $\pi_{4}$ give the average amount of time spent in the other three (expansion) states. Given the matrix $\mathbf{P}$ above, the solution for $\pi$ is

$$
\boldsymbol{\pi}=\left(\begin{array}{l}
0.1479 \\
0.2367 \\
0.2367 \\
0.3787
\end{array}\right)
$$

This implies the chain spends $14.79 \%$ of the time in a recession state and $85.21 \%$ of the time in expansion states, so the average length of expansions relative to that of recessions is $85.21 /(14.79)=5.76$ years.

Idiosyncratic income shocks follow the first order Markov process $\ln \left(Z_{a, t}^{i}\right)=\ln \left(Z_{a-1, t-1}^{i}\right)+$ $\epsilon_{a, t}^{i}$. We directly calibrate the specification in levels:

$$
Z_{a, t}^{i}=Z_{a, t-1}^{i}\left(1+E_{a, t}^{i}\right)
$$

where $E_{a, t}^{i}$ takes on one of two values in each aggregate state:

$$
\begin{aligned}
& E_{a, t}^{i}=\left\{\begin{array}{ll}
\sigma_{E} & \text { with } \operatorname{Pr}=0.5 \\
-\sigma_{E} & \text { with } \operatorname{Pr}=0.5
\end{array}, \quad \text { if } Z_{C, t} \geq E\left(Z_{C, t}\right)\right. \\
& E_{a, t}^{i}=\left\{\begin{array}{ll}
\sigma_{R} & \text { with } \operatorname{Pr}=0.5 \\
-\sigma_{R} & \text { with } \operatorname{Pr}=0.5
\end{array}, \quad \text { if } Z_{C, t}<E\left(Z_{C, t}\right)\right. \\
& \sigma_{R}>\sigma_{E} .
\end{aligned}
$$

Thus, $E\left(Z_{a, t}^{i} / Z_{a, t-1}^{i}\right)=1$.

\subsection{Calibration of Parameters}

Parameters pertaining to the firms' decisions are set as follows. The capital depreciation rate, $\delta$, is set to 0.12 , which corresponds to the average Bureau of Economic Analysis (BEA) depreciation rates for equipment and structures. The housing depreciation rate $\delta_{H}$, is set to 0.025 following Tuzel (2009). Following Kydland and Prescott (1982) and Hansen (1985), the capital share for the non-housing sector is set to $\alpha=0.36$. For the residential investment sector, the value of the capital share in production is taken from a BEA study of gross product 
originating, by industry. The study finds that the capital share in the construction sector ranges from $29.4 \%$ and $31.0 \%$ over the period 1992-1996. We therefore set the capital share in the housing sector to $\nu=0.30 .^{21}$ The adjustment costs for capital in both sectors are assumed to be the same quadratic function of the investment to capital-ratio, $\varphi\left(\frac{I}{K}-\delta\right)^{2}$, where the constant $\varphi$ is chosen to represent a tradeoff between the desire to match aggregate investment volatility simultaneously with the volatility of asset returns. Under this calibration, firms pay a cost only for net new investment; there is no cost to replace depreciated capital. This implies that the total adjustment $\operatorname{cost} \varphi\left(\frac{I}{K}-\delta\right)^{2} K_{t}$ under our calibration is quite small: on average less than one percent of investment, $I_{t}$. The fixed quantity of land/permits available each period, $\overline{\mathcal{L}}$, is set to a level that permits the model to approximately match the housing investment-GDP ratio. In post-war data this ratio is $6 \%$; under our calibration of $\overline{\mathcal{L}}$, the ratio ranges from $5 \%$ to $6.2 \%$. The share of land/permits in the housing production function is set to $10 \%$, to match estimates in Davis and Heathcote (2005), requiring $\phi=0.9$.

Parameters of the individual's problem are set as follows. The subjective time discount factor is set to $\beta=0.923$ at annual frequency, to allow the model to match the mean of a short-term Treasury rate in the data. The survival probability $\pi_{a+1 \mid a}=1$ for $a+1 \leq 65$. For $a+1>65$, we set $\pi_{a+1 \mid a}$ equal to the fraction of households over 65 born in a particular year alive at age $a+1$, as measured by the U.S. Census Bureau. From these numbers, we obtain the stationary age distribution in the model, and use it to match the average earnings over the life-cycle, $G_{a}$, to that observed from the Survey of Consumer Finances. Risk aversion is set to $\sigma=8$, to help the models match the high Sharpe ratio for equity observed in the data. The static elasticity of substitution between $C$ and $H$ is set to $\varepsilon=1$ (Cobb-Douglas utility), following evidence in Davis and Ortalo-Magne (2010) that expenditure shares on housing are approximately constant over time and across U.S. metropolitan statistical areas. The weight, $\chi$ on $C$ in the utility function is set to 0.70 , corresponding to a housing expenditure share of 0.30 . The regime-switching conditional variance in the unit root process in idiosyncratic earnings is calibrated following Storesletten, Telmer, and Yaron (2007) to match their estimates from the Panel Study of Income Dynamics. These are $\sigma_{E}=0.0768$, and $\sigma_{R}=0.1296$.

\footnotetext{
${ }^{21}$ From the November 1997 SURVEY OF CURRENT BUSINESS, "Gross Product by Industry, 1947-96, "by Sherlene K.S. Lum and Robert E. Yuskavage. http://www.bea.gov/scb/account_articles/national/1197gpo/maintext.htm

Gross Product Originating is equal to gross domestic income, whose components can be grouped into categories that approximate shares of labor and capital. Under a Cobb-Douglas production function, these equal shares of capital and labor in output.
} 
To calibrate the costs of equity market participation we follow results in Vissing-Jorgensen (2002), who finds support for the presence of a fixed, per period participation cost, but not for the hypothesis of variable costs. She estimates the size of these costs and finds that they are small, less than 50 dollars per year in year 2000 dollars. These findings motivate our calibration of these costs so that they are no greater than $1 \%$ of per capita, average consumption, denoted $\bar{C}^{i}$ in Table 1.

We set the maximum combined LTV (first and second mortgages) to be $85 \%$, corresponding to $\varpi=15 \%$. It should be emphasized that $1-\varpi$ gives the maximum combined (first and second mortgage) LTV ratio. This will differ from the average LTV ratio because not everyone borrows up to the credit limit.

The fixed and variable housing transactions costs for housing consumption are governed by the parameters $\psi_{0}$ and $\psi_{1}$. These costs are more comprehensive than the costs of buying and selling existing homes. They include costs of any change in housing consumption, such as home improvements and additions, that may be associated with mortgage refinancing and home equity extraction, as well as non-pecuniary psychological costs. We set the values of fixed costs $\psi_{0}$ and variable costs $\psi_{1}$ to be half-way between the values specified in Model 1 and Model 3 in Favilukis, Ludvigson, and Van Nieuwerburgh (2009). The Model 1 parameter values in that paper were intended to match a period prior to the housing boom of 2000-2006 and were anchored by matching the average number of years individuals in the model go without changing housing consumption equal to the average length of residency (in years) for home owners in the Survey of Consumer Finances across the 1989-2001 waves of the survey. Model 3 values in that paper were reduced to match the evidence for a decline in housing transactions costs during the housing boom of 2000-2006. Since 2006, anecdotal evidence suggests that these costs have again risen, though not all the way up to their pre-boom levels. This leaves us with a value for $\psi_{0}$ that is approximately $2.7 \%$ of annual per capita consumption, and a value for $\psi_{1}$ that is approximately $4.3 \%$ of the value of the house $p_{t}^{H} H_{a, t}^{i}$.

\section{Numerical Solution Procedure}

The numerical solution strategy consists of solving the individual's problem taking as given her beliefs about the evolution of the aggregate state variables. With this solution in hand, the economy is simulated for many individuals and the simulation is used to compute the equilibrium evolution of the aggregate state variables, given the assumed beliefs. If the equilibrium evolution differs from the beliefs individuals had about that evolution, a new 
set of beliefs are assumed and the process is repeated. Individuals' expectations are rational once this process converges and individual beliefs coincide with the resulting equilibrium evolution.

The state of the economy is a pair, $\left(Z_{t}, \mu_{t}\right)$, where $\mu_{t}$ is a measure defined over

$$
\mathcal{S}=(\mathcal{A} \times \mathcal{Z} \times \chi \times \mathcal{H})
$$

where $\mathcal{A}=\{1,2, \ldots A\}$ is the set of ages, where $\mathcal{Z}$ is the set of all possible idiosyncratic shocks, where $\chi$ is the set of all possible beginning-of-period financial wealth realizations, and where $\mathcal{H}$ is the set of all possible beginning-of-period housing wealth realizations. That is, $\mu_{t}$ is a distribution of agents across ages, idiosyncratic shocks, financial, and housing wealth. Given a finite dimensional vector to approximate $\mu_{t}$, and a vector of individual state variables

$$
\mu_{t}^{i}=\left(z_{t}^{i}, w_{t}^{i}, h_{t}^{i}\right)
$$

the individual's problem is solved using dynamic programming.

An important step in the numerical strategy is approximating the joint distribution of individuals, $\mu_{t}$, with a finite dimensional object. The resulting approximation, or "bounded rationality" equilibrium has been used elsewhere to solve overlapping generations models with heterogenous agents and aggregate risk, including Krusell and Smith (1998); Ríos-Rull and Sánchez-Marcos (2006); Storesletten, Telmer, and Yaron (2007); Gomes and Michaelides (2008); Favilukis (2008), among others. For our application, we approximate this space with a vector of aggregate state variables other than $B_{F, t}$ and $B_{F, t+1}$ with (in detrended values)

$$
\mu_{t}^{A G}=\left(z_{C, t}, z_{H, t}, k_{t}, S_{t}, h_{t}, p_{t}^{H}, q_{t}\right)
$$

where

$$
K_{t}=K_{C, t}+K_{H, t}
$$

and

$$
S_{t}=\frac{K_{C, t}}{K_{C, t}+K_{H, t}} .
$$

The state variables are the observable aggregate technology shocks, the first moment of the aggregate capital stock, the share of aggregate capital used in production of the consumption good, the aggregate stock of housing, and the relative house price and bond price, respectively. The bond and the house price are natural state variables because the joint distribution of all individuals only matters for the individual's problem in so far as it affects asset prices. Note that knowledge of $K_{t}$ and $S_{t}$ is tantamount to knowledge of $K_{C, t}$ and $K_{H, t}$ separately, and vice versa $\left(K_{C, t}=K_{t} S_{t} ; K_{H, t}=K_{t}\left(1-S_{t}\right)\right)$. 
To solve the model, all variables are divided by the trend component exp $(g t)$ to obtain policy functions and state variables have invariant distributions. In the simulations, we recover the levels of the variables by multiplying them by exp $(g t)$ and returns are multiplied by $(1+g)$.

Because of the large number of state variables and because the problem requires that prices in two asset markets (housing and bond) must be determined by clearing markets every period, the proposed problem is highly numerically intensive. To make the problem tractable, we obviate the need to solve the dynamic programming problem of firms numerically by instead solving analytically for a recursive solution to value function taking the form $V\left(K_{t}\right)=$ $Q_{t} K_{t}$, where $Q_{t}$ (Tobin's $q$ ) is a recursive function. We discuss this below.

In order to solve the individual's dynamic programming problem, the individual must know $\mu_{t+1}^{A G}$ and $\mu_{t+1}^{i}$ as a function of $\mu_{t}^{A G}$ and $\mu_{t}^{i}$ and aggregate shocks $Z_{t+1}=\left(Z_{C, t}, Z_{H, t}, B_{F, t}, B_{F, t+1}\right)$. Here we show that this can be achieved by specifying individuals' beliefs for the laws of motion of four quantities:

A1 $K_{t+1}$,

A2 $p_{t+1}^{H}$,

A3 $q_{t+1}$, and

A4 $\left[\frac{\beta_{t+1} \Lambda_{t+1}}{\Lambda_{t}}\left(Q_{C, t+1}-Q_{H, t+1}\right)\right]$, where $Q_{C, t+1} \equiv V_{C, t+1} / K_{C, t+1}$ and analogously for $Q_{H, t+1}$.

Let $\frac{\beta_{t+1} \Lambda_{t+1}}{\Lambda_{t}} \equiv M_{t+1}$. The beliefs are approximated by a linear function of the aggregate state variables as follows:

$$
\varkappa_{t+1}=A^{(n)}\left(Z_{t}, Z_{t+1}\right) \times \tilde{\varkappa}_{t},
$$

where $A^{(n)}\left(Z_{t}, Z_{t+1}\right)$ is a $4 \times 5$ matrix that depends on the aggregate shocks $Z_{t}$, and $Z_{t+1}$ and where

$$
\begin{aligned}
\varkappa_{t+1} & \equiv\left[K_{t+1}, p_{t+1}^{H}, q_{t+1},\left[M_{t+1}\left(Q_{C, t+1}-Q_{H, t+1}\right)\right]\right]^{\prime}, \\
\widetilde{\varkappa}_{t} & \equiv\left[K_{t}, p_{t}^{H}, q_{t}, S_{t}, H_{t}\right]^{\prime} .
\end{aligned}
$$

We initialize the law of motion (29) with a guess for the matrix $A^{(n)}\left(Z_{t}, Z_{t+1}\right)$, given by $A^{(0)}\left(Z_{t}, Z_{t+1}\right)$. The initial guess is updated in an iterative procedure (described below) to insure that individuals' beliefs are consistent with the resulting equilibrium. 
Given (29), individuals can form expectations of $\mu_{t+1}^{A G}$ and $\mu_{t+1}^{i}$ as a function of $\mu_{t}^{A G}$ and $\mu_{t}^{i}$ and aggregate shocks $Z_{t+1}$. To see this, we employ the following equilibrium relation (as shown below) linking the investment-capital ratios of the two production sectors:

$$
\frac{I_{H, t}}{K_{H, t}}=\frac{I_{C, t}}{K_{C, t}}+\frac{1}{2 \varphi} E_{t}\left[M_{t+1}\left(Q_{C, t+1}-Q_{H, t+1}\right)\right] .
$$

Moreover, note that $E_{t}\left[M_{t+1}\left(Q_{C, t+1}-Q_{H, t+1}\right)\right]$ can be computed from (29) by integrating the 4 th equation over the possible values of $Z_{t+1}$ given $\tilde{\varkappa}_{t}$ and $Z_{t}$.

Equation (30) is derived by noting that the consumption firm solves a problem taking the form

$$
V\left(K_{C, t}\right)=\max _{I_{C, t}, N_{C, t}} Z_{C, t} K_{C t}^{\alpha} N_{C, t}^{1-\alpha}-w_{t} N_{C, t}-I_{C, t}-\varphi\left(\frac{I_{C, t}}{K_{C, t}}-\delta\right)^{2}+E_{t}\left[M_{t+1} V\left(K_{C, t+1}\right)\right] .
$$

The first-order condition for optimal labor choice implies $N_{C, t}=\left(\frac{Z_{C, t}(1-\alpha)}{w_{t}}\right)^{1 / \alpha} K_{C, t}$. Substituting this expression into $V\left(K_{C, t}\right)$, the optimization problem may be written

$$
\begin{aligned}
V\left(K_{C, t}\right) & =\max _{I_{t}} X_{C, t} K_{C, t}-I_{C, t}-\varphi\left(\frac{I_{C, t}}{K_{C, t}}-\delta\right)^{2} K_{C, t}+E_{t}\left[M_{t+1} V\left(K_{C, t+1}\right)\right](31) \\
\text { s.t. } \quad K_{C, t+1} & =(1-\delta) K_{C, t}+I_{C, t}
\end{aligned}
$$

where

$$
X_{C, t} \equiv \alpha\left(\frac{Z_{C, t}}{w_{t}}(1-\alpha)\right)^{(1-\alpha) / \alpha} Z_{C, t}
$$

is a function of aggregate variables over which the firm has no control.

The housing firms solves

$$
\begin{aligned}
V\left(K_{H, t}\right)= & \max _{I_{H, t}, N_{H, t}} p_{t}^{H} Z_{H, t}\left(\mathcal{L}_{t}\right)^{1-\phi}\left(K_{H, t}^{\nu} N_{H, t}^{1-\nu}\right)^{\phi}-w_{t} N_{H, t}-I_{H, t}-p_{t}^{L} \mathcal{L}_{t} \\
& -\varphi\left(\frac{I_{H, t}}{K_{H, t}}-\delta\right)^{2}+E_{t}\left[M_{t+1} V\left(K_{H, t+1}\right)\right] .
\end{aligned}
$$

The first-order conditions for optimal labor and land/permits choice for the housing firm imply that $N_{H, t}=k_{N} K_{H, t}, \mathcal{L}_{t}=k_{L} K_{H, t}$, where

$$
\begin{aligned}
k_{N} & =\left(k_{1}^{\phi} k_{2}^{1-\phi}\right)^{1 / \nu \phi} \\
k_{L} & =\left(k_{1}^{\phi(1-\nu)} k_{2}^{1-\phi(1-\nu)}\right)^{1 / \phi \nu} \\
k_{1} & =p_{t}^{H} Z_{H, t} \phi(1-\nu) / w_{t} \\
k_{2} & =p_{t}^{H} Z_{H, t}(1-\phi) / p_{t}^{L} .
\end{aligned}
$$


Substituting this expression into $V\left(K_{H, t}\right)$, the optimization problem may be written

$$
\begin{aligned}
V\left(K_{H, t}\right) & =\max _{I_{t}} X_{H t} K_{H, t}-I_{H, t}-\varphi\left(\frac{I_{H, t}}{K_{H, t}}-\delta\right)^{2} K_{H, t}+E_{t}\left[M_{t+1} V\left(K_{H, t+1}\right)\right\} \\
\text { s.t. } \quad K_{H, t+1} & =(1-\delta) K_{H, t}+I_{H, t}
\end{aligned}
$$

where

$$
X_{H, t}=p_{t}^{H} Z_{H, t} \phi \nu k_{N}^{(1-\nu) \phi} k_{L}^{1-\phi} .
$$

Let $s$ index the sector as either consumption, $C$, or housing, $H$. We now guess and verify that for each firm, $V\left(K_{s, t+1}\right)$, for $s=C, H$ takes the form

$$
V\left(K_{s, t+1}\right)=Q_{s, t+1} K_{s, t+1}, \quad s=C, H
$$

where $Q_{s, t+1}$ depends on aggregate state variables but is not a function of the firm's capital stock $K_{s, t+1}$ or investment $I_{s, t}$. Plugging (34) into (31) we obtain

$$
V\left(K_{s, t}\right)=\max _{I_{t}} X_{s, t} K_{s, t}-I_{t}-\varphi\left(\frac{I_{s, t}}{K_{s, t}}-\delta\right)^{2} K_{s, t}+E_{t}\left[M_{t+1} Q_{s, t+1}\right]\left[(1-\delta) K_{s, t}+I_{s, t}\right] .
$$

The first-order conditions for the maximization (35) imply

$$
\frac{I_{s, t}}{K_{s, t}}=\delta+\frac{E_{t}\left[M_{t+1} Q_{s, t+1}\right]-1}{2 \varphi} .
$$

Substituting (36) into (35) we verify that $V\left(K_{s, t}\right)$ takes the form $Q_{s, t} K_{s, t}$ :

$$
\begin{aligned}
V\left(K_{s, t}\right) \equiv & Q_{s, t} K_{s, t}=X_{s, t} K_{s, t}-\left(\delta+\frac{E_{t}\left[M_{t+1} Q_{s, t+1}\right]-1}{2 \varphi}\right) K_{s, t}-\varphi\left(\frac{E_{t}\left[M_{t+1} Q_{s, t+1}\right]-1}{2 \varphi}\right)^{2} K_{s, t} \\
& +(1-\delta)\left(E_{t}\left[M_{t+1} Q_{s, t+1}\right]\right) K_{s, t}+E_{t}\left[M_{t+1} Q_{s, t+1}\right]\left(\delta+\frac{E_{t}\left[M_{t+1} Q_{s, t+1}\right]-1}{2 \varphi}\right) K_{s, t} .
\end{aligned}
$$

Rearranging terms, it can be shown that $Q_{s, t}$ is a recursion:

$$
Q_{s, t}=X_{s, t}+(1-\delta)+2 \varphi\left(\frac{E_{t}\left[M_{t+1} Q_{s, t+1}\right]-1}{2 \varphi}\right)+\varphi\left(\frac{E_{t}\left[M_{t+1} Q_{s, t+1}\right]-1}{2 \varphi}\right)^{2}
$$

Since $Q_{s, t}$ is a function only of $X_{s, t}$ and the expected discounted value of $Q_{s, t+1}$, it does not depend on the firm's own $K_{s, t+1}$ or $I_{s, t}$. Hence we verify that $V\left(K_{s, t}\right)=Q_{s, t} K_{s, t}$. Although $Q_{s, t}$ does not depend on the firm's individual $K_{s, t+1}$ or $I_{s, t}$, in equilibrium it will be related to the firm's investment-capital ratio via:

$$
Q_{s, t}=X_{s, t}+(1-\delta)\left[1+2 \varphi\left(\frac{I_{s, t}}{K_{s, t}}-\delta\right)\right]+\varphi\left(\frac{I_{s, t}}{K_{s, t}}\right)^{2}-2 \varphi \delta\left(\frac{I_{s, t}}{K_{s, t}}\right)
$$


as can be verified by plugging (36) into (37). Note that (36) holds for the two representative firms of each sector, i.e., $Q_{C, t}$ and $Q_{H, t}$, thus we obtain (30) above.

With (38), it is straightforward to show how individuals can form expectations of $\mu_{t+1}^{A G}$ and $\mu_{t+1}^{i}$ as a function of $\mu_{t}^{A G}$ and $\mu_{t}^{i}$ and aggregate shocks $Z_{t+1}$. Given a grid of values for $K_{t}$ and $S_{t}$ individuals can solve for $K_{C, t}$ and $K_{H, t}$ from $K_{C, t}=K_{t} S_{t}$ and $K_{H, t}=K_{t}\left(1-S_{t}\right)$. Combining this with beliefs about $K_{t+1}$ from (29), individuals can solve for $I_{t} \equiv I_{C, t}+I_{H, t}$ from $K_{t+1}=(1-\delta) K_{t}+I_{t}$. Given $I_{t}$ and beliefs about $\left[\frac{\beta^{k} \Lambda_{t+k}}{\Lambda_{t}}\left(Q_{C, t+1}-Q_{H, t+1}\right)\right]$ from (29), individuals can solve for $I_{C, t}$ and $I_{H, t}$ from (30). Given $I_{H, t}$ and the accumulation equation $K_{H, t+1}=(1-\delta) K_{H, t}+I_{H, t}$, individuals can solve for $K_{H, t+1}$. Given $I_{C, t}$ individuals can solve for $K_{C, t+1}$ using the accumulation equation $K_{C, t+1}=(1-\delta) K_{C, t}+I_{C, t}$. Using $K_{H, t+1}$ and $K_{C, t+1}$, individuals can solve for $S_{t+1}$. Given a grid of values for $H_{t}, H_{t+1}$ can be computed from $H_{t+1}=\left(1-\delta_{H}\right) H_{t}+Y_{H, t}$, where $Y_{H, t}=Z_{H, t}\left(\mathcal{L}_{t}\right)^{1-\phi}\left(K_{H, t}^{\nu} N_{H, t}^{1-\nu}\right)^{\phi}$ is obtained from knowledge of $Z_{H, t}, K_{H, t}$ (observable today), from the equilibrium condition $\mathcal{L}_{t}=L$, and by combining (22) and (24) to obtain the decomposition of $N_{t}$ into $N_{C, t}$ and $N_{H, t}$. Equation (29) can be used directly to obtain beliefs about $q_{t+1}$ and $p_{t+1}^{H}$.

To solve the dynamic programming problem individuals also need to know the equity values $V_{C, t}$ and $V_{H, t}$. But these come from knowledge of $Q_{s, t}\left(\right.$ using $(38)$ ) and $K_{s, t}$ via $V_{s, t}=$ $Q_{s, t} K_{s, t}$ for $s=C, H$. Values for dividends in each sector are computed from

$$
\begin{aligned}
D_{C, t} & =Y_{C, t}-I_{C, t}-w_{t} N_{C, t}-\phi_{C}\left(\frac{I_{C, t}}{K_{C, t}}\right) K_{C, t} \\
D_{H, t} & =p_{t}^{H} Y_{H, t}-I_{H, t}-p_{t}^{L} \mathcal{L}_{t}-w_{t} N_{H, t}-\phi_{H}\left(\frac{I_{H, t}}{K_{H, t}}\right) K_{H, t}
\end{aligned}
$$

and from

$$
w_{t}=(1-\alpha) Z_{j, t} K_{j, t}^{\alpha} N_{j, t}^{-\alpha}=(1-\nu)(1-\phi) p_{t}^{H} Z_{H, t} \mathcal{L}_{t}^{\phi} K_{H, t}^{\nu(1-\phi)} N_{H, t}^{-\phi(1-\nu)-\nu}
$$

and by again combining (22) and (24) to obtain the decomposition of $N_{t}$ into $N_{C, t}$ and $N_{H, t}$. Finally, the evolution of the aggregate technology shocks $Z_{t+1}$ is given by the first-order Markov chain described above; hence agents can compute the possible values of $Z_{t+1}$ as a function of $Z_{t}$.

Values for $\mu_{t+1}^{i}=\left(Z_{t+1}^{i}, W_{t+1}^{i}, H_{t+1}^{i}\right)$ are given from all of the above in combination with the first order Markov process for idiosyncratic income $\log \left(Z_{a, t}^{i}\right)=\log \left(Z_{a-1, t-1}^{i}\right)+\epsilon_{a, t}^{i}$. Note that $H_{t+1}^{i}$ is a choice variable, while $W_{t+1}^{i}=\theta_{t}^{i}\left(V_{C, t+1}+V_{H, t+1}+D_{C, t+1}+D_{H, t+1}\right)+B_{t+1}^{i}$ requires knowing $V_{s, t+1}=Q_{s, t+1} K_{s, t+1}$ and $D_{s, t+1}, s=C, H$ conditional on $Z_{t+1}$. These in turn depend on $I_{s, t+1}, s=C, H$ and may be computed in the manner described above by 
rolling forward one period both the equation for beliefs (29) and accumulation equations for $K_{C, t+1}$, and $K_{H, t+1}$.

The individual's problem, as approximated above, may be summarized as follows (where we drop age subscripts when no confusion arises and express trending variables as detrended): $v_{a, t}\left(\mu_{t}^{A G}, b_{F, t}, b_{F, t+1}, \mu_{t}^{i}\right)=\max _{h_{t+1}^{i}, \theta_{t+1}^{i}, b_{t+1}^{i}} U\left(c_{t}^{i}, h_{t}^{i}\right)+\beta \pi_{i} E_{t}\left[v_{a+1, t+1}\left(\mu_{t+1}^{A G}, b_{F, t}, b_{F, t+1}, \mu_{t+1}^{i}\right)\right] \quad$ s.t.

The above problem is solved subject to (6), (7), (8), and (9) if the individual of working age, and subject to the analogous versions of (6), (7), (8), and (9) (using pension income in place of wage income), if the individual is retired. The problem is also solved subject to an evolution equation for the state space:

$$
\mu_{t+1}^{A G}=\Gamma^{(n)}\left(\mu_{t}^{A G}, Z_{t+1}\right) .
$$

$\Gamma^{(n)}$ is the system of forecasting equations that is obtained by stacking all the beliefs from (29) and accumulation equations into a single system. This dynamic programming problem is quite complex numerically because of a large number of state variables but is otherwise straightforward. Its implementation is described below.

Next we simulate the economy for a large number of individuals using the policy functions from the dynamic programming problem. The continuum of individuals born each period is approximated by a number large enough to insure that the mean and volatility of aggregate variables is not affected by idiosyncratic shocks. We check this by simulating the model for successively larger numbers of individuals in each age cohort and checking whether the mean and volatility of aggregate variables changes. We have solved the model for several different numbers of agents. For numbers ranging from a total of 2,400 to 40,000 agents in the population we found no significant differences in the aggregate allocations.

An additional numerical complication is that two markets (the housing and bond market) must clear each period. This makes $p_{t}^{H}$ and $q_{t}$ convenient state variables: the individual's policy functions are a response to a menu of prices $p_{t}^{H}$ and $q_{t}$, Given values for $Y_{H, t}, H_{a+1, t+1}^{i}$, $H_{a, t}^{i}, B_{a, t}^{i}$ and $B_{t}^{F}$ form the simulation, and given the menu of prices $p_{t}^{H}$ and $q_{t}$ and the beliefs $(29)$, we then choose values for $p_{t+1}^{H}$ and $q_{t+1}$ that clear markets in $t+1$. The initial allocations of wealth and housing are set arbitrarily to insure that prices in the initial period of the simulation, $p_{1}^{H}$ and $q_{1}$, clear markets. However, these values are not used since each simulation includes an initial burn-in period of 150 years that we discard for the final results.

Using data from the simulation, we calculate (A1)-(A4) as linear functions of $\tilde{\varkappa}_{t}$ and an initial guess $A^{(0)}$. In particular, for every $Z_{t}$ and $Z_{t+1}$ combination we regress (A1)- 
(A4) on $K_{t}, S_{t}, H_{t}, p_{t}^{H}$, and $q_{t}$. This is used to calculate a new $A^{(n)}=A^{(1)}$ which is used to re-solve for the entire equilibrium. We continue repeating this procedure, updating the sequence $\left\{A^{(n)}\right\}, n=0,1,2, \ldots$ until (1) the coefficients in $A^{(n)}$ between successive iterations is arbitrarily small, (2) the regressions have high $R^{2}$ statistics, and (3) the equilibrium is invariant to the inclusion of additional state variables such as additional lags and/or higher order moments of the cross-sectional wealth and housing distribution.

The $R^{2}$ statistics for the four equations (A1)-(A4) are $(.999, .999, .989, .998)$, respectively. The lowest $R^{2}$ is for the bond price equation. We found that successively increasing the number of agents (beyond 2400) successively increases the $R^{2}$ in the bond price equation, without affecting the equilibrium allocations or prices. However, we could not readily increase the number of agents beyond 40,000 because attempts to do so exceeded the available memory on a workstation computer. Our interpretation of this finding is that the equilibrium is unlikely to be affected by an approximation using more agents, even though doing so could result in an improvement in the $R^{2}$ of the bond equation. For this reason, and because of the already high computational burden required to solve the model, we stopped at the slightly lower level of accuracy for the bond forecasting regression as compared to the other forecasting regressions.

\section{Numerical Solution to Individual's Dynamic Programming Problem}

We now describe how the individual's dynamic programming problem is solved.

First we choose grids for the continuous variables in the state space. That is we pick a set of values for $w^{i}, h^{i}, k, h, S, p^{H}$, and $q$. Because of the large number of state variables, it is necessary to limit the number of grid points for some of the state variables given memory/storage limitations. We found that having a larger number of grid points for the individual state variables was far more important than for the aggregate state variables, in terms of the effect it had on the resulting allocations. Thus we use a small number of grid points for the aggregate state variables but compensate by judiciously choosing the grid point locations after an extensive trial and error experimentation designed to use only those points that lie in the immediate region where the state variables ultimately reside in the computed equilibria. As such, a larger number of grid points for the aggregate state variables was found to produce very similar results to those reported using only a small number of points. We pick 25 points for $w_{t}^{i}, 12$ points for $h_{t}^{i}$, three points for $k_{t}, h_{t}, S_{t}, p_{t}^{H}, b_{F, t}, b_{F, t+1}$ and four points for $q_{t}$. The grid for $w^{i}$ starts at the borrowing constraint and ends far above the maximum wealth reached in simulation. This grid is very dense around typical values of 
financial wealth and is sparser for high values. The housing grid is constructed in the same way.

Given the grids for the state variables, we solve the individual's problem by value function iteration, starting for the oldest (age $A$ ) individual and solving backwards. The oldest individual's value function for the period after death is zero for all levels of wealth and housing (alternately it could correspond to an exogenously specified bequest motive). Hence the value function in the final period of life is given by $v_{A}=\max _{h_{t+1}^{i}, \theta_{t+1}^{i}, b_{t+1}^{i}} U\left(c_{A}^{i}, h_{A}^{i}\right)$ subject to the constraints above for (39). Given $v_{A}$ (calculated for every point on the state space), we then use this function to solve the problem for a younger individual (aged $A-1$ ). We continue iterating backwards until we have solved the youngest individual's (age 1) problem. We use piecewise cubic splines (Fortran methods PCHIM and CHFEV) to interpolate points on the value function. Any points that violate a constraint are assigned a large negative value. 


\section{References}

Aiyagari, S. R., and M. Gertler (1991): "Asset Returns with Transactions Costs and Uninsurable Individual Risk," Journal of Monetary Economics, 27, 311-331.

Basak, S., And D. Cuoco (1998): "An Equilibrium Model with Restricted Stock Market Participation," Review of Financial Studies, 11(2), 309-341.

Benninga, S., and A. Protopapadakis (1990): "Leverage, Time Preference and the Equity Premium Puzzle," Journal of Monetary Economics, 25, 49-58.

Bernanke, B. S. (2011): "International Capital Flows and the Returns to Safe Assets," Banque de France Financial Stability Review, 15, 13-26.

Caballero, R. J. (2009): "Discussion of "Global Imbalances and the Financial Crisis: Products of Common Causes, by M.Obstfeld and K.Rogoff"," Unpublished paper, M.I.T.

Caballero, R. J., E. Fahri, and P.-O. Gourinchas (2008a): "An Equilibrium Model of "Global Imbalances" and Low Interest Rates," American Economic Review, 98(1), 358393.

(2008b): "Financial Crash, Commodity Prices, and Global Imbalances," Brookings Papers on Economic Activity, pp. 1-55.

Caballero, R. J., and A. Krishnamurthy (2009): "Global Imbalances and Financial Fragility," American Economic Review Papers and Proceedings, 99, 584-588.

Calvo, G. A., A. Izquierdo, and E. Talvi (2006): "Sudden Stops and Phoenix Miracles in Emerging Markets," American Economic Review, 96(2), 405-410.

Campbell, S. D., and Z. Hercowitz (2006): "The Role of Households' Collateralized Debt in Macroeconomic Stabilization," Unpublished paper, Federal Reserve Board.

Carceles Poveda, E., and D. Coen-Pirani (2009): "Owning Capital or Being Shareholders: An Equivalence Result with Incomplete Markets," Unpublished paper, SUNY Stony Brook. 
Cooper, R. N. (2007): "Living With Global Imbalances," Brookings Papers on Economic Activity, 2, 91-107.

Corbae, D., And E. Quintin (2009): "Mortgage Innovation and the Foreclosure Boom," Unpublished paper, University of Texas at Austin.

Davis, M., and F. Ortalo-Magne (2010): "Household Expenditures, Wages, Rents," Review of Economic Dynamics, forthcoming.

Davis, M. A., And J. Heathcote (2005): "Housing and the Business Cycle," International Economic Review, 46(3), 751-784.

Dooley, M., D. Folkerts-Landau, and P. Garber (2005): International Financial Stability: Asia, Interest Rates, and the Dollar. Deutsche Bank Global, New York.

Fahri, E., P. O. Gourinchas, and H. Rey (2011): "Reforming the International Monetary System," Unpublished paper, Harvard University.

Favilukis, J. (2008): "Wealth Inequality, Stock Market Participation, and the Equity Premium," Unpublished paper, London School of Economics.

Favilukis, J., S. C. Ludvigson, and S. Van Nieuwerburgh (2009): "The Macroeconomic Effects of Housing Wealth, Housing Finance and Limited Risk Sharing in General Equilibrium," Unpublished paper, New York University.

Fernández-Villaverde, J., and D. Krueger (2005): "Consumption and Saving over the Life Cycle: How Important are Consumer Durables?," Unpublished paper, University of Pennsylvania.

Glaeser, E. L., J. Gyourko, and R. Saks (2005): "Why Have Housing Prices Gone Up?," American Economic Review Papers and Proceedings, 95(2), 329-333.

Gomes, F., And A. Michaelides (2008): "Asset Pricing with Limited Risk Sharing and Heterogeneous Agents," Review of Financial Studies, 21(1), 415-448.

Gopinath, G., and B. Neiman (2011): "Trade Adjustment and Productivity in Large Crises," Unpublished paper, Harvard University.

Hansen, G. D. (1985): "Indivisible Labor and the Business Cycle," Journal of Monetary Economics, 16, 309-327. 
Heaton, J., And D. Lucas (1996): "Evaluating the Effects of Incomplete Markets on Risk Sharing and Asset Pricing," Journal of Political Economy, 104(3), 443-87.

Hodrick, R., and E. C. Prescott (1997): "Post-War U.S. Business Cycles: A Descriptive Empirical Investigation," Journal of Money, Credit, and Banking, 29, 1-16.

Iacoviello, M., and M. Pavan (2009): "Housing and Debt Over the Life Cycle and Over the Business Cycle," Unpublished paper, Boston College and University College Dublin.

Kiyotaki, N., A. Michaelides, and K. Nikolov (2008): "Winners and Losers in Housing Markets," Unpublished paper, London School of Economics.

Kohn, D. L. (2002): "Panel: Implications of Declining Treasury Debt. What Should the Federal Reserve Do as Treasury Debt Is Repaid?," Journal of Money, Credit and Banking, $34(3), 941-945$.

Krishnamurthy, A., and A. Vissing-Jorgensen (2010): "The Aggregate Demand for Treasury Debt," Unpublished paper, Kellog School, Northwestern University.

Krueger, D., and H. Lustig (2010): "When is Market Incompleteness Irrelevant for the Price of Aggregate Risk (and when is it not)?," Journal of Economic Theory, 145, 1-41.

Krusell, P., and A. A. Smith (1998): "Income and Wealth Heterogeneity in the Macroeconomy," Journal of Political Economy, 106(5), 867-896.

Kydland, F., and E. C. Prescott (1982): "Time to Build and Aggregate Fluctuations," Econometrica, 50, 343-360.

Lucas, D. J. (1994): "Asset Pricing with Undiversifiable Income Risk and Short Sales Constraints: Deepening the Equity Premium Puzzle," Journal of Monetary Economics, $34(3), 325-341$.

Lustig, H., and S. VAn Nieuwerburgh (2005): "Housing Collateral, Consumption Insurance and Risk Premia: an Empirical Perspective," Journal of Finance, 60(3), 1167-1219.

(2007): "Can Housing Collateral Explain Long-Run Swings in Asset Returns?," Unpublished paper, New York University.

(2010): "How Much Does Household Collateral Constrain Regional Risk Sharing?," Review of Economic Dynamics, 13(2), 265-294. 
Luttmer, E. G. J. (1999): "What Level of Fixed Costs Can Reconcile Consumption and Stock Returns?," Journal of Political Economy, 107(5), 969-997.

Mendoza, E. G., V. Quadrini, and J.-V. Rios-Rull (2007): "Financial Integration, Financial Deepness and Global Imbalances," NBER Working Paper No. 12909.

Obstfeld, M., and K. Rogoff (2009): "Global Imbalances and the Financial Crisis: Products of Common Causes," Unpublished Paper, Harvard University.

Ortalo-Magné, F., and S. Rady (2006): "Housing Market Dynamics: On the Contribution of Income Shocks and Credit Constraints," Review of Economic Studies, 74, 459-485.

Peterson, B. (2006): "Aggregate Uncertainty, Individual Uncertainty and Illiquidity: Housing and the Business Cycle," Unpublished paper, Indiana University.

Piazzesi, M., And M. Schneider (2008): "Inflation And The Price Of Real Assets," Unpublished paper, Standford Univeristy.

Ríos-Rull, J., And V. SÁnchez-Marcos (2006): “An Aggregate Economy with Different Size Houses," Unpublished paper, University of Minnesota.

Storesletten, K., C. I. Telmer, and A. Yaron (2004): "Cyclical Dynamics in Idiosyncratic Labor-Market Risk," Journal of Political Economy, 112(3), 695-717.

(2007): "Asset pricing with idiosyncratic risk and overlapping generations," Review of Economic Dynamics, 10(4), 519-548.

Telmer, C. I. (1993): “Asset-Pricing Puzzles and Incomplete Markets," Journal of Finance, 48, 1803-1832.

Tuzel, S. (2009): “Corporate Real Estate Holdings and the Cross Section of Stock Returns," Unpublished paper, Marshall School, University of Southern California.

Vissing-Jorgensen, A. (2002): "Towards and Explanation of Household Portfolio Choice Heterogeneity: Nonfinancial Income and Participation Cost Structures," Unpublished manuscript, Northwestern University, Kellog School of Management.

Warnock, F. E., And V. C. Warnock (2009): "International Capital Flows and U.S. Interest Rates," Journal of International Money and Finance, 28, 903-919. 


\section{Figure 1: Foreign Holdings of U.S. Treasuries and Agencies}

The figure plots foreign holdings of U.S. Treasuries (squares) and U.S. Agencies (circles). U.S. Agencies denotes both the corporate bonds issued by the Government Sponsored Enterprizes and the mortgage-backed securities guaranteed by them. The solid lines denote the amount of long-term and short-term holdings, in billions of U.S. dollars, as measured against the left axis. The dashed lines denote the long-term foreign holdings relative to the total amount of outstanding long-term (marketable) debt. The data are from the U.S. Treasury International Capital System's annual survey of foreign portfolio holdings of U.S. securities. The foreign holdings data are available for December 1974, 1978, 1984, 1989, 1994, 1997, March 2000, and annually from June 2002 until June 2010.

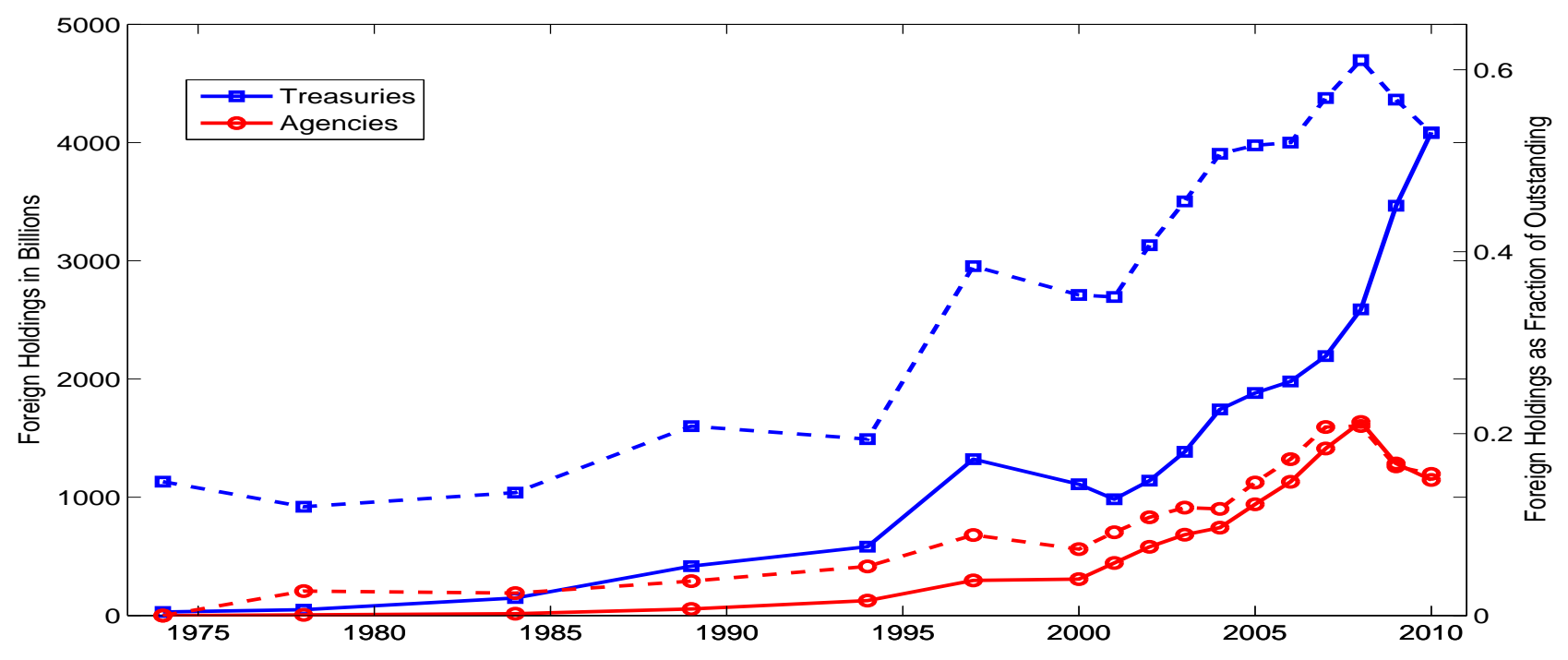




\section{Figure 2: Foreign Holdings Relative to U.S. Trend GDP}

The solid line denotes foreign holdings of U.S. Treasuries and Agencies relative to U.S. trend GDP (squares). Trend GDP is computed with a Hodrick-Prescott filter. The dashed line (stars) asks what the foreign holdings relative to trend GDP would have been if the foreign holdings relative to the amount of debt outstanding declined the amount they did, but the amount of debt outstanding relative to trend GDP was held at 2008 values for the years 2009 and 2010. The foreign holdings data are available for December 1974, 1978, 1984, 1989, 1994, 1997, March 2000, and annually from June 2002 until June 2010.

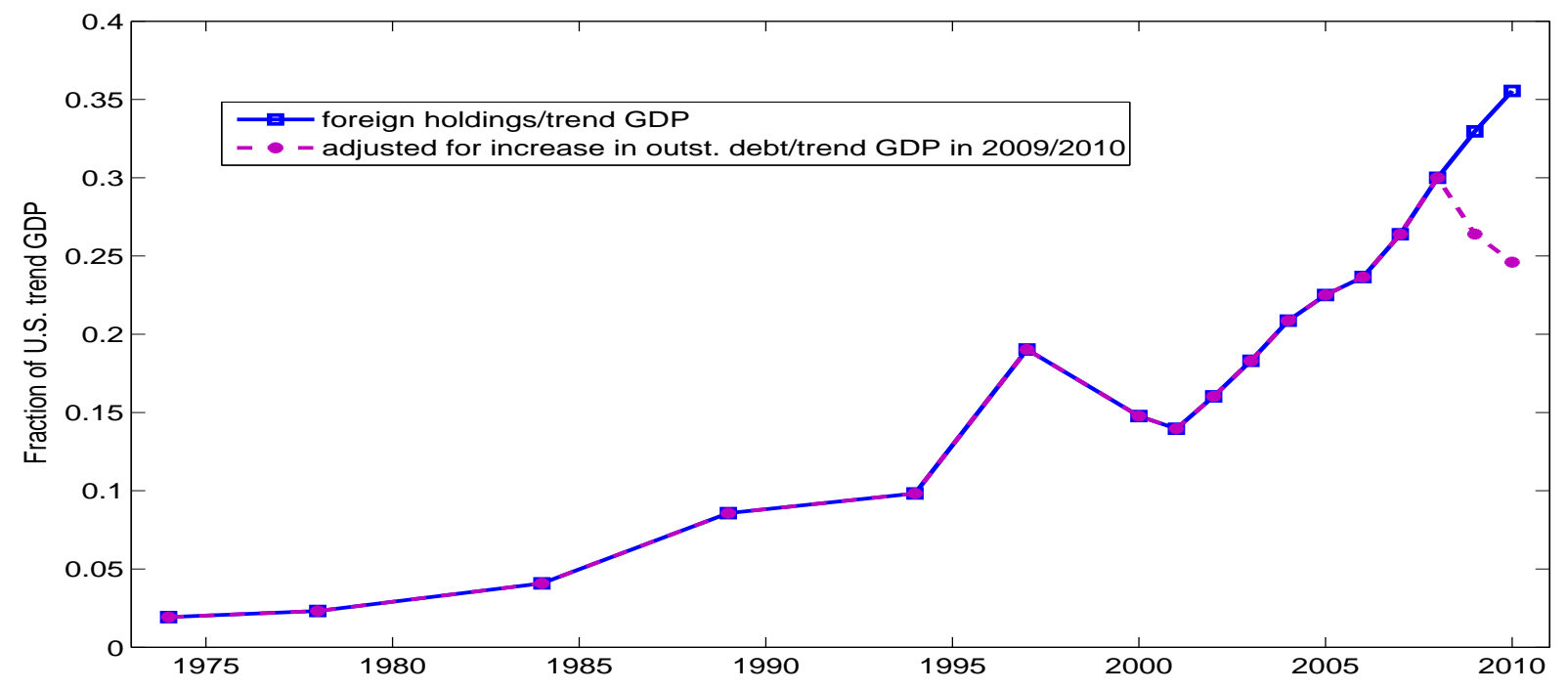




\section{Figure 3: Net Foreign Holdings Relative to U.S. Trend GDP}

The solid line (squares) denotes total net foreign holdings of long-term securities (the net foreign liability position of the U.S.) relative to U.S. trend GDP. Net foreign holdings are defined as foreign holdings of U.S. securities minus U.S. holdings of foreign securities. All U.S. holdings of foreign securities classify as risky holdings because they carry at least exchange rate risk. We define as safe the foreign holdings of U.S. Treasuries and Agencies. The dashed line denotes the thus constructed net foreign holdings in risky assets (circles), while the dotted line (stars) denotes the net foreign holdings in safe assets. The data are from the U.S. Treasury International Capital System's annual survey of foreign portfolio holdings of U.S. securities. The data are available for December 1994, December 1997, March 2000, and annually from June 2002 until June 2010.

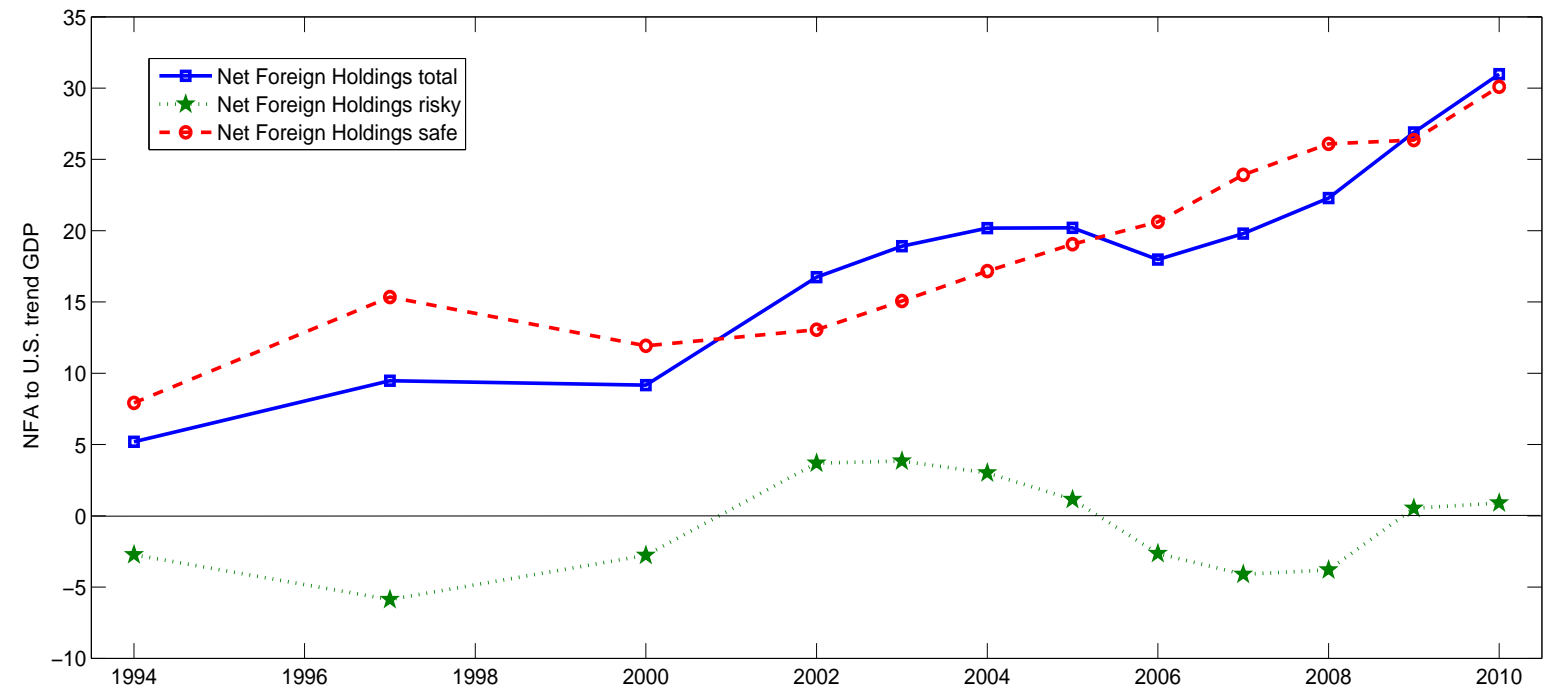




\section{Figure 4: Welfare by Age}

The left (right) panel plots the EV of an increase (decrease) in foreign holdings by age. The dashed line (circles) is the EV integrated out against the distribution of last period's bond holdings $b_{F, t}$. In particular, the dashed lines report for all age buckets (denoted by subscript $a$ ) the following welfare measure:

$$
E V_{a}=\iiint \int\left\{\left(\frac{\bar{v}_{a}\left(b_{F, t}, b_{F, t}+\Delta, Z_{t}^{i}, w_{t}^{i}, h_{t}^{i}\right)}{\bar{v}_{a}\left(b_{F, t}, b_{F, t}, Z_{t}^{i}, w_{t}^{i}, h_{t}^{i}\right)}\right)^{\frac{\sigma}{\sigma-1}} d Z_{t}^{i} d w_{t}^{i} d h_{t}^{i} d b_{F, t}\right\},
$$

where the change $\Delta$ in foreign holdings relative to trend GDP is set to equal $\Delta=\left(1-\rho_{F}\right) \bar{b}+\rho_{F} b_{F, t}+\sigma_{F} \cdot 1$ (increase) or $\Delta=$ $\left(1-\rho_{F}\right) \bar{b}+\rho_{F} b_{F, t}+\sigma_{F} \cdot(-1)$ (decrease). Under the calibration discussed in the text, $\Delta=2 \%$ in quintile 1 (1.7\% at the average) in the left panel and $-2.2 \%$ in quintile $5(-1.8 \%$ at the average) in the right panel. The solid line (squares) in each panel is the EV when the previous-period's holdings $b_{F, t}$ are in either the lowest, $b_{F 1}$, quintile (left panel) or the highest, $b_{F 10}$ quintile (right panel); i.e., the solid line reports

$$
E V_{a \mid b_{F 1}}=\iiint \int_{b_{F, t} \in b_{F 1}}\left\{\left(\frac{\bar{v}_{a}\left(b_{F, t}, b_{F, t}+\Delta, Z_{t}^{i}, w_{t}^{i}, h_{t}^{i}\right)}{\bar{v}_{a}\left(b_{F, t}, b_{F, t}, Z_{t}^{i}, w_{t}^{i}, h_{t}^{i}\right)}\right)^{\frac{\sigma}{\sigma-1}} d Z_{t}^{i} d w_{t}^{i} d h_{t}^{i} d b_{F, t}\right\}
$$

in the left panel and analogously for the highest quintile in the right panel. The age buckets are 21-30, 31-40, 41-50, 51-60, 61-70, 71-80, 81 and above.
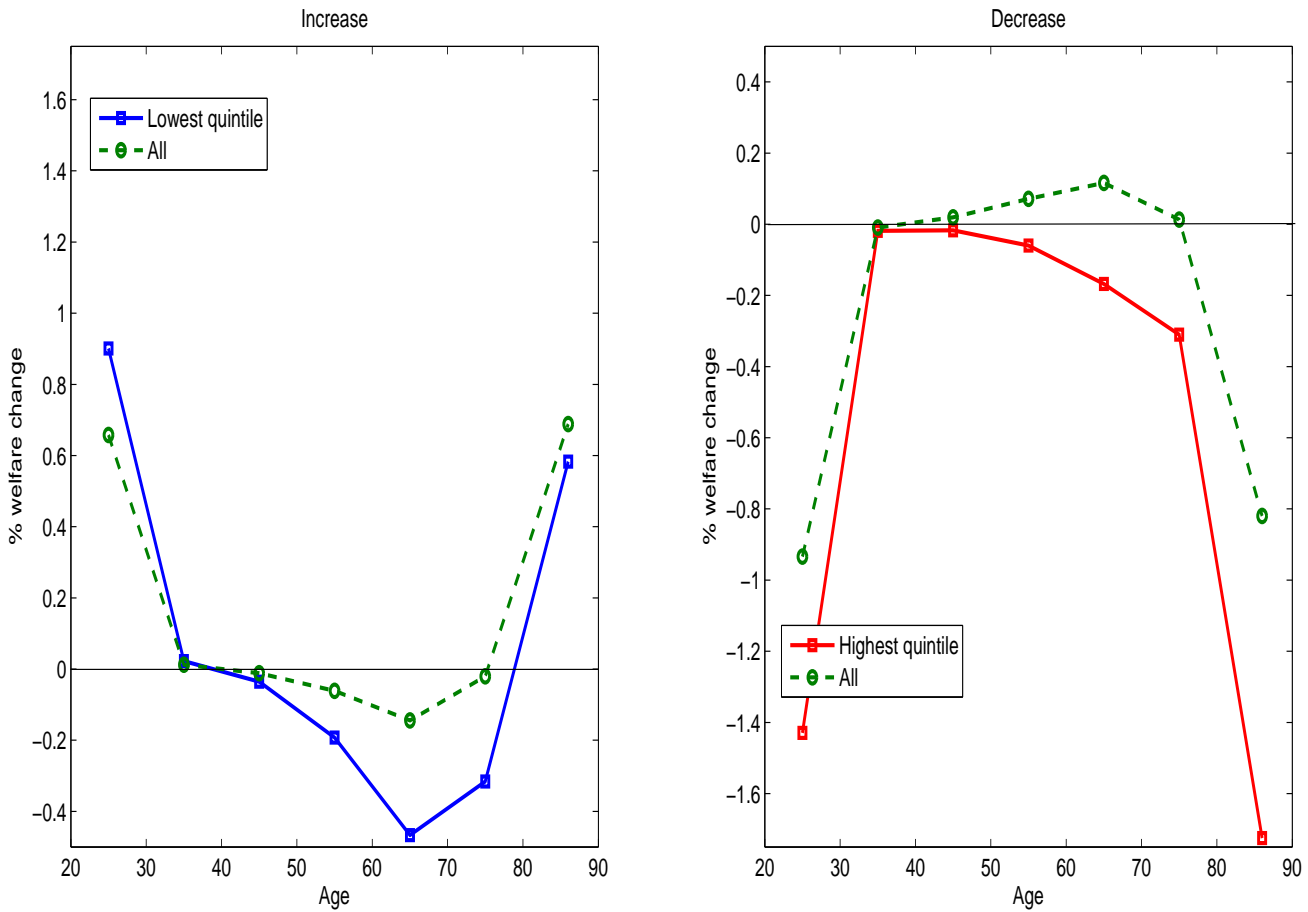


\section{Figure 5: Welfare by Age, Income, and Financial Wealth}

The left (right) panel plots the EV of a decrease in foreign holdings by age for various income (net worth) groups. The solid line (squares) in the left (right) panel is the EV for those households in a given age bucket that are in the lowest one-third of income (net worth). The dashed line (circles) is the EV for those households in a given age bucket that are in the middle one-third of income (wealth). The dotted line (diamonds) is the EV for those households in a given age bucket that are in the middle one-third of income (wealth). The EV integrates out against the distribution of current-period and previous-period foreign bond holdings. The age buckets are 21-30, 31-40, 41-50, 51-60, 61-70, 71-80, 81 and above.
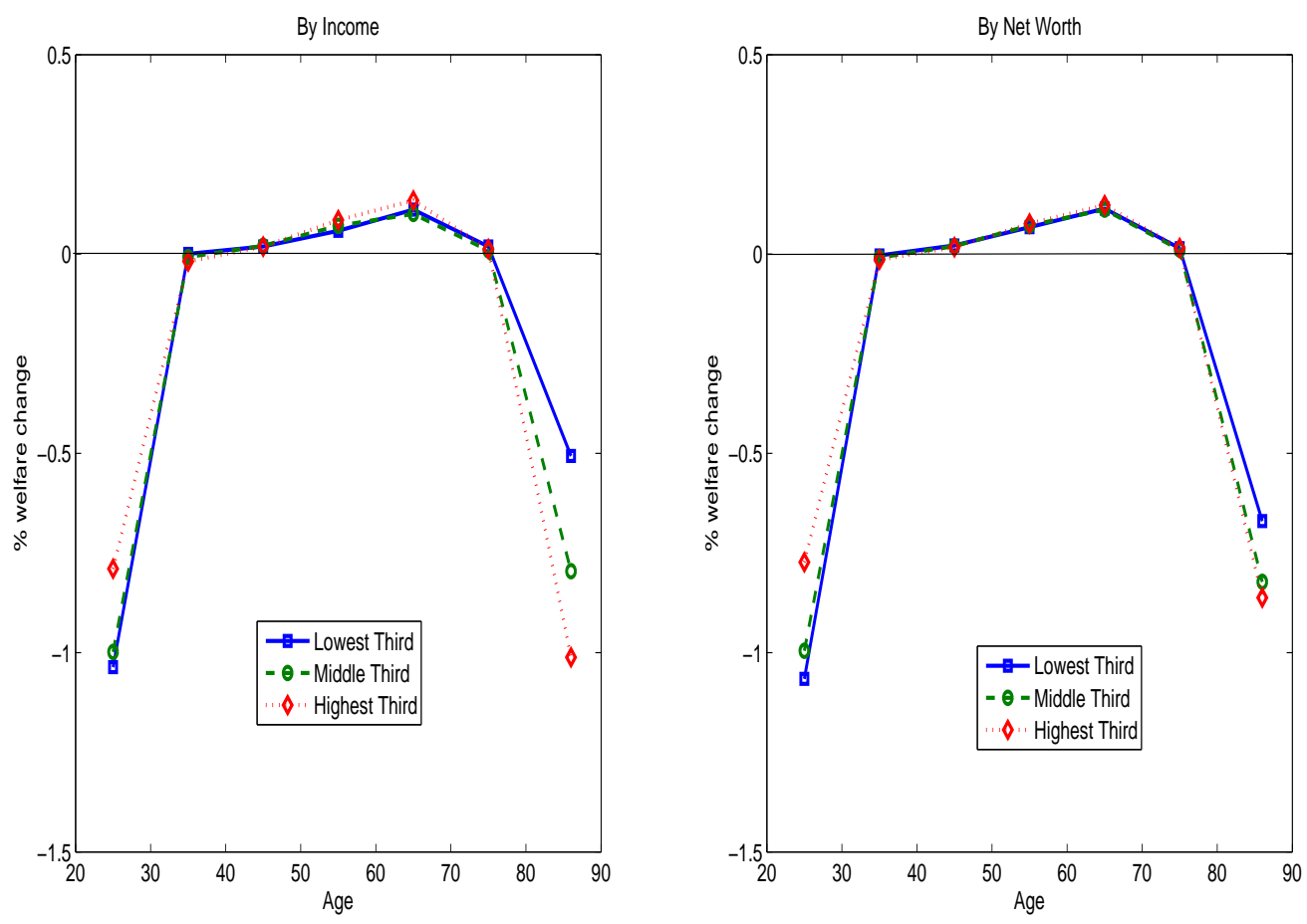


\section{Figure 6: Welfare for Newborns}

The figure plots the EV of a large decline in foreign holdings for a newborn (under the veil of ignorance). The measure compares the value function of a newborn, born in the 5th quintile of current foreign holdings $b_{F, t+1}=b_{5}$, to the welfare of a newborn, born in a world with current holdings in each of the other quintiles $b_{F, t+1}=b_{F i}$, for $i=1, \cdots, 5$ (indicated by diamonds):

$$
E V_{0}\left(b_{i}\right)=\int\left\{\left(\frac{\bar{v}_{0}\left(b_{F, t}, b_{F i}, 1,0, \bar{h}_{0}\right)}{\bar{v}_{0}\left(b_{F, t}, b_{F 5}, 1,0, \bar{h}_{0}\right)}\right)^{\frac{\sigma}{\sigma-1}}-1\right\} d b_{F, t},
$$

where $\bar{h}_{0}$ is the age- 0 housing wealth agents are born with (the lowest point on the housing grid). The EV integrates out against the distribution of previous-period holdings $b_{F, t}$. The fifth point (most to the right) is 0 by construction.

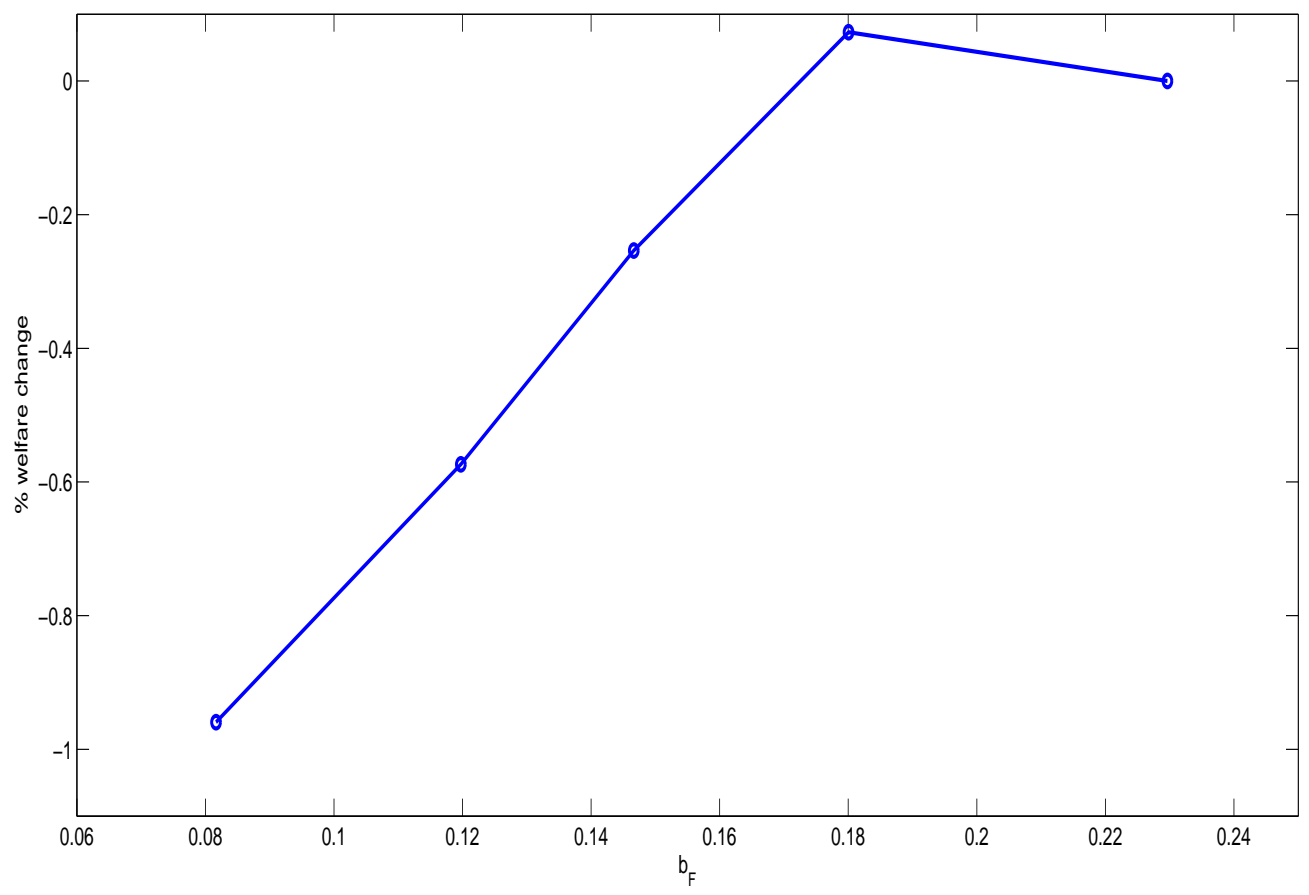


Table 1: Calibration

\begin{tabular}{|c|c|c|c|}
\hline & Parameter & Description & Value \\
\hline \multicolumn{4}{|c|}{ Production } \\
\hline 1 & $\left\{\phi_{C}(\cdot), \phi_{H}(\cdot)\right\}$ & adj. cost fcn. & 2 \\
\hline 2 & $\delta$ & deprec., $K_{C}, K_{H}$ & $12 \%$ \\
\hline 3 & $\delta_{H}$ & depreciation, $H$ & $2.5 \%$ \\
\hline 4 & $\alpha$ & capital share, $Y_{C}$ & 0.36 \\
\hline 5 & $\nu$ & capital share, $Y_{H}$ & 0.30 \\
\hline 6 & $\phi$ & non-land share in construction & 0.90 \\
\hline \multicolumn{4}{|c|}{ Preferences } \\
\hline 7 & $1 / \sigma$ & risk aversion & 8 \\
\hline 8 & $\beta$ & time disc factor & 0.9 \\
\hline 9 & $\varepsilon$ & elast of sub, $C, H$ & 1 \\
\hline 10 & $\chi$ & weight on $C$ & 0.70 \\
\hline \multicolumn{4}{|c|}{ Demographics and Income } \\
\hline 11 & $G_{a}$ & age earnings profile & $\mathrm{SCF}$ \\
\hline 12 & $\pi_{a+1 \mid a}$ & survival prob & mortality tables \\
\hline 13 & $\sigma_{E}$ & st. dev ind earnings in boom & 0.0768 \\
\hline 14 & $\sigma_{R}$ & st. dev ind earnings in bust & 0.1298 \\
\hline \multicolumn{4}{|c|}{ Transaction costs and collateral constraint } \\
\hline 15 & $\bar{F}$ & equity mkt fixed participation cost & $1 \% \bar{C}^{i}$ \\
\hline 16 & $\psi_{0}$ & housing mkt fixed transaction cost & $2.7 \% \bar{C}^{i}$ \\
\hline 17 & $\psi_{1}$ & housing mkt variable transaction cost & $4.3 \%$ \\
\hline 18 & $\varpi$ & minimum combined downpayment & $15 \%$ \\
\hline \multicolumn{4}{|c|}{ Foreign Holdings } \\
\hline 19 & $\bar{b}$ & mean for. holdings/trend GDP & 0.148 \\
\hline 20 & $\rho_{F}$ & persistence for. holdings/trend GDP & 0.95 \\
\hline 21 & $\sigma_{F}$ & innovation volatility for.holdings/trend GDP & $1.7 \%$ \\
\hline
\end{tabular}


Table 2: Real Business Cycle Moments

Panel A denotes business cycle statistics in annual U.S. data from 1953 until 2010. The data combine information from NIPA Tables 1.1.5, 3.9.5, and 2.3.5. Output $\left(Y=Y_{C}+p^{H} Y_{H}+C_{H}\right)$ is gross domestic product minus government expenditures. Total consumption $\left(C_{T}\right)$ is total private sector consumption (housing and non-housing). Housing consumption $\left(C_{H}=\mathcal{R} * H\right)$ is consumption of housing services. Non-housing consumption $(C)$ is total private sector consumption minus housing services. Housing investment $\left(p^{H} Y_{H}\right)$ is residential investment. Non-housing investment $(I)$ is the sum of private sector non-residential structures, equipment and software, and changes in inventory. Total investment is denoted $I_{T}$ (residential and non-housing). Net exports are - 0.02 of GDP on average, and are not reported in the table. For each series in the data, we first deflate by the disposable personal income deflator, We then construct the trend with a Hodrick-Prescott (1980) filter with parameter $\lambda=100$. Finally, we construct detrended data as the log difference between the raw data and the HP trend, multiplied by 100. The standard deviation (first column), correlation with GDP (second column), and the first-order autocorrelation are all based on these detrended series. The autocorrelation AC is a one-year correlation in data and model. The share of GDP (fourth column) is based on the raw data. Panel B denotes the same statistics for the benchmark model.

\begin{tabular}{ccccc}
\hline \hline & \multicolumn{4}{c}{ Panel A: Data (1953-2010) } \\
& st.dev. & corr. w. GDP & AC & share of gdp \\
\hline$Y$ & 2.57 & 1.00 & 0.45 & 1.00 \\
$C_{T}$ & 1.91 & 0.89 & 0.65 & 0.82 \\
$C$ & 2.13 & 0.89 & 0.63 & 0.67 \\
$C_{H}$ & 1.33 & 0.57 & 0.67 & 0.14 \\
$I_{T}$ & 8.75 & 0.92 & 0.39 & 0.20 \\
$I$ & 8.99 & 0.84 & 0.32 & 0.14 \\
$p^{H} Y_{H}$ & 14.30 & 0.68 & 0.61 & 0.06 \\
\hline
\end{tabular}

Panel B: Model

\begin{tabular}{ccccc} 
& st.dev. & corr. w. GDP & AC & share of gdp \\
\hline$Y$ & 2.74 & 1.00 & 0.11 & 1.00 \\
$C_{T}$ & 2.12 & 0.91 & 0.02 & 0.72 \\
$C$ & 2.01 & 0.85 & 0.03 & 0.47 \\
$C_{H}$ & 2.62 & 0.89 & 0.02 & 0.24 \\
$I_{T}$ & 8.74 & 0.77 & 0.01 & 0.28 \\
$I$ & 9.00 & 0.78 & 0.03 & 0.23 \\
$p^{H} Y_{H}$ & 13.48 & 0.41 & 0.05 & 0.05 \\
\hline \hline
\end{tabular}




\section{Table 3: Quantities by Foreign Holdings}

The table reports the first and second moments of real quantities by level of and changes in foreign holdings in the model. The quantity variables are as defined in Table 2 Panel A reports means of the quantity variables, whereas Panel B reports standard deviations. In each panel, the "all" column reports the unconditional moment from a long simulation. The column "high $B_{F, t}$ " ("low $B_{F, t}$ ") reports the conditional moment of the dated-t variable, conditional on the foreign holdings level $b_{F, t}$, which was chosen at time $t-1$, being in the highest (lowest) $1 / 2$ of observations on the level of foreign holdings in the same long simulation. The column "high $\Delta B_{F}$ " ("low $\Delta B_{F}$ " ) reports the conditional moment of the dated-t variable, conditional on the foreign holdings change $\Delta b_{F}=b_{F, t+1}-b_{F, t}$, which is known at time $t$, being in the highest (lowest) $1 / 2$ of observations on the change in foreign holdings in the same long simulation.

\begin{tabular}{lccccc|ccccc}
\hline \hline & \multicolumn{5}{c|}{ Panel A: Mean } & \multicolumn{4}{c}{ Panel B: Standard deviation } \\
& all & $b_{F, t} \mathrm{H}$ & $b_{F, t} \mathrm{~L}$ & $\Delta b_{F} \mathrm{H}$ & $\Delta b_{F} \mathrm{~L}$ & all & $b_{F, t} \mathrm{H}$ & $b_{F, t} \mathrm{~L}$ & $\Delta b_{F} \mathrm{H}$ & $\Delta b_{F} \mathrm{~L}$ \\
\hline$Y$ & 2.28 & 2.30 & 2.27 & 2.29 & 2.28 & 2.74 & 2.72 & 2.75 & 2.67 & 2.78 \\
$C_{T}$ & 1.63 & 1.63 & 1.63 & 1.65 & 1.62 & 2.12 & 2.15 & 2.07 & 1.95 & 1.91 \\
$C$ & 1.07 & 1.07 & 1.07 & 1.09 & 1.06 & 2.01 & 2.06 & 1.95 & 1.82 & 1.69 \\
$C_{H}$ & 0.56 & 0.56 & 0.56 & 0.56 & 0.55 & 2.62 & 2.61 & 2.63 & 2.47 & 2.61 \\
$I_{T}$ & 0.64 & 0.66 & 0.63 & 0.69 & 0.60 & 8.74 & 8.95 & 8.49 & 5.79 & 7.42 \\
$I$ & 0.52 & 0.53 & 0.51 & 0.56 & 0.49 & 9.00 & 9.29 & 8.67 & 6.53 & 7.90 \\
$p^{H} Y_{H}$ & 0.12 & 0.12 & 0.12 & 0.13 & 0.11 & 13.48 & 13.28 & 13.65 & 10.59 & 12.24 \\
\hline \hline
\end{tabular}




\section{Table 4: Sensitivity to Changes in Foreign Holdings}

The second and third columns report the slope coefficients $\beta_{F, t}$ and $\beta_{\Delta b_{F}}$ of a multiple regression of the log change in a variable between $\mathrm{t}+1$ and $\mathrm{t}$ on a constant, the foreign holdings level $b_{F, t}$ (chosen in period $\mathrm{t}-1$ ), and the foreign holdings flow between $\mathrm{t}$ and $\mathrm{t}+1 \Delta b_{F, t+1}$ :

$$
\log X_{t+1}-\log X_{t}=\alpha+\beta_{F} b_{F, t}+\beta_{\Delta b_{F}} \Delta b_{F, t+1}+\epsilon_{t}
$$

The constant in the regression is omitted. The first seven rows are the same real variables defined in Table 2 (not HP de-trended). The left-hand side variables in the eighth and ninth rows are the growth rate in the beginning-of-period capital $\left(\log K_{t+2}-\log K_{t+1}\right)$ and housing stock $\left(\log H_{t+2}-\log H_{t+1}\right)$, respectively. The tenth row is the aggregate wage, the eleventh row the aggregate house value, and the last row the aggregate mutual fund capitalization.

\begin{tabular}{lcc}
\hline \hline Var & $\beta_{F}$ & $\beta_{\Delta b_{F}}$ \\
\hline \multicolumn{3}{l}{ Panel A: RBC Moments } \\
1. $Y$ & -0.01 & 0.19 \\
2. $C_{T}$ & -0.03 & 0.57 \\
3. $C$ & -0.04 & 0.65 \\
4. $C_{H}$ & -0.02 & 0.40 \\
5. $I_{T}$ & -0.19 & 3.88 \\
6. $I$ & -0.17 & 3.64 \\
7. $p^{H} Y_{H}$ & -0.24 & 4.98 \\
8. $K$ & 0.00 & 0.45 \\
9. $H$ & 0.02 & 0.08 \\
10. $\mathcal{W}$ & 0.00 & 0.12 \\
Panel B: Asset & Prices \\
11. $p^{H} H$ & -0.09 & 1.91 \\
12. $V$ & -0.07 & 1.72 \\
\hline \hline
\end{tabular}




\section{Table 5: Asset Pricing Moments}

The second column (data 1) reports the observed asset pricing moments, listed in the first column, in annual 1953-2010 data. The equity return $R_{S}$ is the value-weighted CRSP stock market return minus the realized inflation rate over the course of the year. The risk-free rate is measured as the nominal yield on a one-year government bond from the CRSP Fama-Bliss data set in the last month of the preceding year minus the realized inflation rate over the course of the year. The price deflator is the same as in Table 2 The housing return $R_{H}$ in data1 is the aggregate value of residential real estate wealth in the fourth quarter of the year from the Flow of Funds plus the consumption of housing services summed over the four quarters of the year from NIPA divided by the value of residential real estate in the fourth quarter of the preceding year. We subtract inflation to express the return in real terms and population growth in order to correct for the growth in housing quantities due to population growth. The third column reports moments for the annual 1976-2010 sample. The housing return in data 2 uses the seasonally adjusted repeat-sale national house price index from Core Logic and the seasonally-adjusted rental price index for shelter from the Bureau of Labor Statistics. It assumes a price-rent ratio in 1975 equal to the one in data 1 . We then use the quarterly price and rent indices to construct quarterly returns and price-rent ratios over the 1976-2010 period. We construct annual returns by compounding the quarterly returns during the year. We subtract realized inflation from realized housing returns to form real housing returns. The stock return and risk-free rate in data 2 are the same as in data 1 , but measured over the shorter sample. The fourth column reports the unconditional asset pricing moments from a long simulation of the model. The fifth (sixth) column reports the same time-t moments, but conditional on being in the highest $1 / 2$ (lowest $1 / 2$ ) of foreign holdings levels $b_{F, t}$, chosen at $\mathrm{t}-1$. The seventh (eight) column reports the same time-t moments, but conditional on being in the highest $1 / 2$ (lowest 1/2) of foreign holdings changes $\Delta b_{F, t}$ between t-1 and t. For example, the last column, seventh row reports the equity risk premium (the time-t expectation of the excess return between $t$ and $t+1$ ), conditional on having experienced a foreign outflow between t-1 and t. The first and second rows reports first and second moments of the one-period risk-free rate. The third and fourth (fifth and sixth) rows report first and second moments of the unlevered (levered) physical capital return (i.e., stock market return). The seventh row reports the average excess return, i.e., in excess of the riskfree rate. The eight row reports the Sharpe ratio, defined as the average excess return divided by the standard deviation of the excess return. Rows nine through twelve report the analogous return moments for the aggregate housing market. For columns five through 8, row thirteen (fourteen) reports the change in the house price-rent ratio (stock market price-dividend ratio), measured as the percentage change relative to the "all" periods sample in column 4.

\begin{tabular}{|c|c|c|c|c|c|c|c|}
\hline & data 1 & data 2 & all & $b_{F, t} \mathrm{H}$ & $b_{F, t} \mathrm{~L}$ & $\Delta b_{F} \mathrm{H}$ & $\Delta b_{F} \mathrm{~L}$ \\
\hline 1. $E\left[R_{f}\right]$ & 1.86 & 2.29 & 1.60 & 1.02 & 2.19 & -2.06 & 5.25 \\
\hline 2. $S t d\left[R_{f}\right]$ & 2.06 & 2.28 & 4.85 & 4.82 & 4.79 & 2.63 & 3.61 \\
\hline 3. $E\left[R_{K}\right]$ & & & 4.29 & 4.05 & 4.51 & 1.09 & 7.47 \\
\hline 4. $S t d\left[R_{K}\right]$ & & & 6.80 & 7.05 & 6.53 & 5.67 & 6.32 \\
\hline 5. $E\left[R_{S}\right]$ & 8.73 & 9.35 & 6.08 & 6.08 & 6.06 & 3.18 & 8.95 \\
\hline 6. $S t d\left[R_{S}\right]$ & 18.78 & 17.38 & 9.59 & 10.02 & 9.14 & 8.85 & 9.44 \\
\hline 7. $E\left[R_{S}-R_{f}\right]$ & 6.87 & 7.06 & 4.48 & 5.06 & 3.87 & 5.24 & 3.70 \\
\hline 8. $S R\left[R_{S}\right]$ & 0.37 & 0.41 & 0.51 & 0.56 & 0.47 & 0.61 & 0.42 \\
\hline 9. $E\left[R_{H}\right]$ & 11.20 & 9.83 & 11.33 & 11.08 & 11.56 & 7.95 & 14.68 \\
\hline 10. $S t d\left[R_{H}\right]$ & 5.82 & 7.55 & 7.04 & 7.09 & 6.99 & 5.73 & 6.60 \\
\hline 11. $E\left[R_{H}-R_{f}\right]$ & 9.35 & 7.54 & 9.72 & 10.06 & 9.38 & 10.01 & 9.43 \\
\hline 12. $S R\left[R_{H}\right]$ & 1.55 & 0.94 & 1.78 & 1.81 & 1.76 & 1.90 & 1.67 \\
\hline 13. $\Delta\left(p^{H} / \mathcal{R}\right)$ & & & -- & 1.02 & -1.02 & 2.48 & -2.46 \\
\hline 14. $\Delta(V / D)$ & & & -- & 11.35 & -11.35 & 44.76 & -44.69 \\
\hline
\end{tabular}

